\title{
Theoretical Model and Experimental Study of Dynamic Hot Rolling
}

\author{
Yanbo Yang and Yan Peng *
}

National Engineering Research Center for Equipment and Technology of Cold Rolld Strip, Yanshan University, Qinhuangdao 066004, China; yangyb_ls@outlook.com

* Correspondence: pengyanysu@outlook.com or pengyan@ysu.edu.cn

Citation: Yang, Y.; Peng, Y.

Theoretical Model and Experimental Study of Dynamic Hot Rolling. Metals 2021, 11, 1346. https://doi.org/ $10.3390 /$ met11091346

Academic Editor: José Valdemar Fernandes

Received: 22 July 2021

Accepted: 23 August 2021

Published: 26 August 2021

Publisher's Note: MDPI stays neutral with regard to jurisdictional claims in published maps and institutional affiliations.

Copyright: (c) 2021 by the authors. Licensee MDPI, Basel, Switzerland. This article is an open access article distributed under the terms and conditions of the Creative Commons Attribution (CC BY) license (https:// creativecommons.org/licenses/by/ $4.0 /)$.

\begin{abstract}
At present, the commonly used hot rolling model is only applicable to the static rolling process. However, to study the dynamic rolling process, a dynamic rolling model with roll vertical movement velocity parameters is required. In this study, the influence of the vertical movement velocity of the rolls on the rolling process is considered, and a dynamic rolling process model is proposed when the roll gap is reduced during the hot rolling dynamic rolling process. Mathematically, the model is based on the upper limit method. The model considers the influence of the dynamic rolling process on the length of the deformation zone, establishes a dynamic velocity field model and an average deformation rate model, and then solves the total power of the rolling process. Finally, the dynamic rolling force equation is given. Compared with the experimental results, the dynamic rolling model in this paper has high accuracy with an average error of $4 \%$. In addition, the influence of roll vertical velocity on rolling parameters is discussed, which provides a basis for the study of the dynamic rolling process.
\end{abstract}

Keywords: metal forming; dynamic rolling; hot rolling

\section{Introduction}

An accurate rolling model is a key to producing high-quality steel products. At present, the research on the static rolling process has been relatively complete. However, when the rolls have vertical velocities, the plate thickness, strip velocity, rolling force, and other parameters are affected. The changing law of the parameters is also different from static rolling, referred to as the dynamic rolling process. The model established based on the static rolling process is not suitable for the dynamic rolling process. It is difficult to predict the parameters of the dynamic rolling process accurately. Therefore, a clearly defined mathematical model must be established to study the dynamic rolling process comprehensively. The typical dynamic rolling mainly includes the vibration phenomenon during the rolling process, variable thickness rolling, etc. The establishment of the dynamic model provides more accurate predictions for the dynamic rolling process and enriches the rolling model.

In the past few decades, the research of rolling models has always been a hot spot in compressive bulk forming processes. In order to better understand the rolling process, a large number of models have been established. Orowan [1] described the pressure distribution of the roller contact arc through a differential equation, taking into account the non-uniform deformation of the strip, and believed that there is no relative sliding between the strip and the surface of the roll. However, the Orowan model is not easy to solve. Based on the differential equation of contact arc unit pressure established by Orowan, Sims [2] simplified the Orowan model. They put forward the stress state coefficient and finally established the rolling force solution model. Because it better reflects the characteristics of hot rolling, the model was widely used. Li et al. [3] established the rolling force model by the method of fluid mechanics. The non-uniform deformation is considered in the model, which is more straightforward in form. However, relative velocity and factor of relative visibility in the model can not be calculated directly, which makes it difficult to solve 
the model. The friction state of the contact arc in the hot rolling process is complicated. Chen et al. [4] established a rolling force model in the hot rolling process. The model is considered based on the von-Kalman equation, the sliding zone, adhesion zone, and stagnation zone of the strip surface friction.

In addition, the energy method is also widely used in rolling modeling. Oh et al. [5] obtained the analytical solution of the rolling torque by establishing a three-dimensional velocity field and assuming that the friction force during the rolling process is constant. This model considers the influence of shear deformation on the rolling torque, but the rolling force is not discussed. Sezek et al. [6] used the upper bound method to analyze the strip rolling process. Unlike other researchers, the plastic deformation boundary function at the entrance and the strip width extension function was first set by this study. The velocity field was obtained through the dual-stream function. Finally, the total power of the deformation process was obtained. Zhang et al. [7] established a rolling force model for predicting the rolling process of ultra-thick plates. The model adopted the two-dimensional velocity field, and the shear deformation of the strip in the thickness direction was also considered. In addition, the deformation permeability coefficient (it has to do with the through-thickness strain heterogeneity) is introduced into the model. In order to facilitate the calculation of the model, the yield function is simplified. Liu et al. [8] established an exponential velocity field. They considered the characteristics of hot rolling, so the friction force was assumed to be a constant value and then established a rolling model for the hot rolling process. This model does not consider the non-uniform deformation in the thickness direction of the strip, and the MY yield criterion is adopted, which reduces the difficulty of solving. Li et al. [9] established an analytical model for the rolling force of hot rolling, and this model adopted the three-dimensional sinusoidal velocity field. However, this study also did not consider the non-uniform deformation of the strip thickness direction.

However, the rolling process models established by the researchers as mentioned above are all static models, and the influence of the vertical movement velocity of the roll on the rolling is not considered, which makes it impossible to predict the parameters of the dynamic rolling process accurately. The dynamic rolling model established by Hu et al. [10] considered the influence of the moving velocity of the roll in the vertical and horizontal directions on the rolling process. Meanwhile, the strip is considered uniformly deformed, and the friction between the roll and the strip is the shear deformation resistance. Consequently, it is more suitable for predicting the hot rolling process. However, in this model, only the change in the length of the deformation zone caused by the velocity of the roll is considered. Gao et al. [11] conducted research on the vertical vibration of a cold rolled strip and established the dynamic unit rolling force balance differential equation in the deformation zone. The dynamic model only considered the influence of the vertical movement of the roll on the length of the deformation zone. Cao et al. [12] established a dynamic rolling force model for the vertical vibration process of cold rolling and separately analyzed the roll gap increase and roll gap reduction process. It is assumed that the strip is assumed to be in a uniformly deformed state. However, the model only considers the influence of the dynamic process on the length of the deformation zone. Hu et al. [13] established an enhanced version of the dynamic rolling force model, which introduced the roll motion velocity into the model according to the plastic flow equation. Therefore, the influence of the roll motion velocity of the model on the length of the deformation zone and the rate of plastic deformation is considered simultaneously, and the dynamic rolling process is fully described. This model is more complete than the previous model and fully considers the characteristics of dynamic rolling. Yang et al. [14] proposed a dynamic rolling force model when the roll gap increases. The model adopts the energy method to establish the strip deformation velocity field during the dynamic rolling process, and successfully introduces the vertical motion velocity of the roll into the rolling model. The influence of the velocity of the roll movement on the length of the deformation zone and the rate of plastic deformation are both considered. However, the velocity field, boundary conditions, and integral limit of the strip deformation are different in reducing the roll gap and the 
increase of the roll gap. Consequently, if the same deformation conditions are used for analysis and modeling, it is unreasonable and inaccurate. Therefore, the model cannot calculate the roll gap reduction process.

Unfortunately, no well-defined mathematical model is describing the dynamic rolling process of roll gap reduction. This paper aims to establish a dynamic rolling model based on the energy method of the roll gap reduction process. The effects of plastic deformation rate and dynamic boundary conditions are included compared with the experimental results of dynamic hot rolling.

\section{Dynamic Rolling Process Model}

The process of roll gap reduction during dynamic rolling is shown in Figures 1 and 2. The moving velocity of the top work roll is $h_{c}^{\prime}$ in the negative direction of the $y$-axis, and the bottom work roll moves in the opposite direction. In addition, when the dynamic roll gap is reduced, the exit position will move to the x-direction, and additional deformation zone II will appear. When the strip width-to-thickness ratio is greater than 10, it can be considered that the rolling deformation process is a plane strain problem. The coordinate system is a static coordinate system with a fixed space. The origin is at the midpoint of the straight line connecting the centers of the two work rolls. The deformation zone is symmetrical; therefore, the geometric model only considers a quarter. The work roll is assumed to be a cylinder with radius $R$. The roller surface equation and its first derivative equation of deformation zone I are respectively expressed as:

$$
\left\{\begin{array}{l}
h_{x}=h_{c}+R-\sqrt{R^{2}-x^{2}} \\
h^{\prime}{ }_{x}=\frac{x}{\sqrt{R^{2}-x^{2}}}=-\tan \theta \\
x=-R \sin \theta
\end{array}\right.
$$

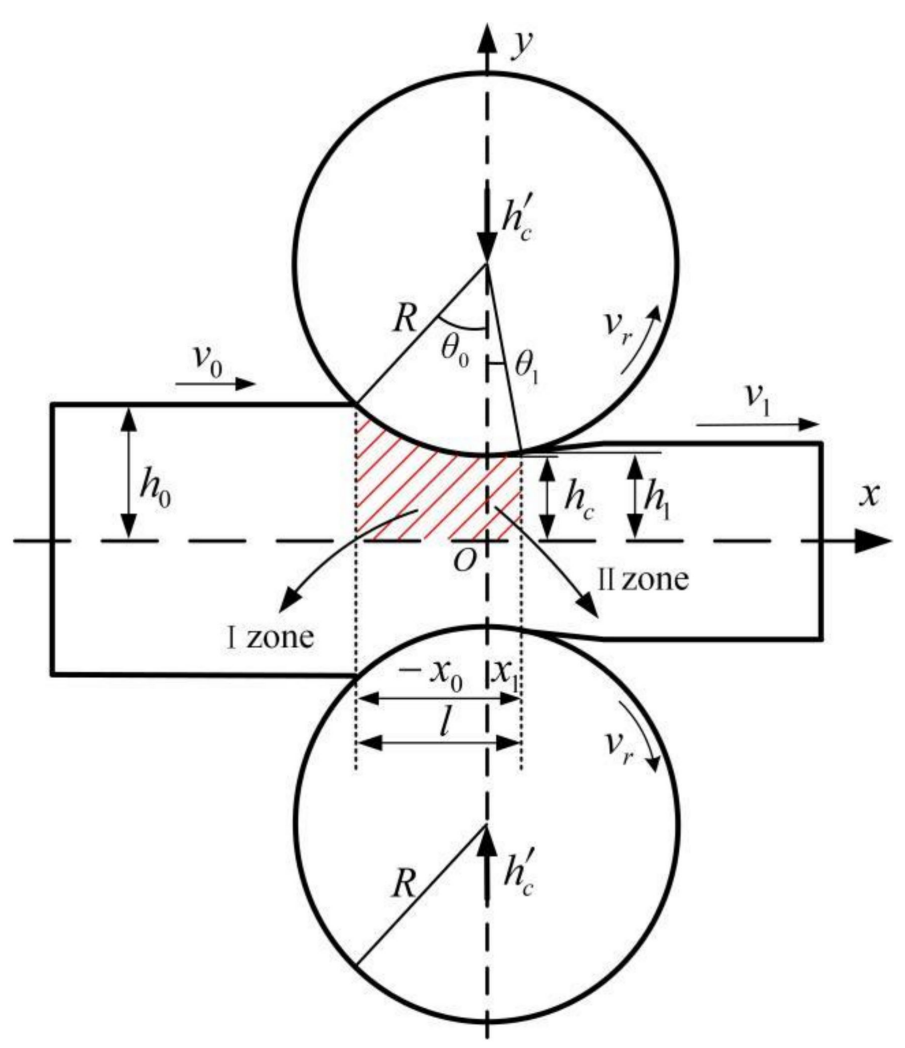

Figure 1. Roll bite geometry during dynamic rolling. 


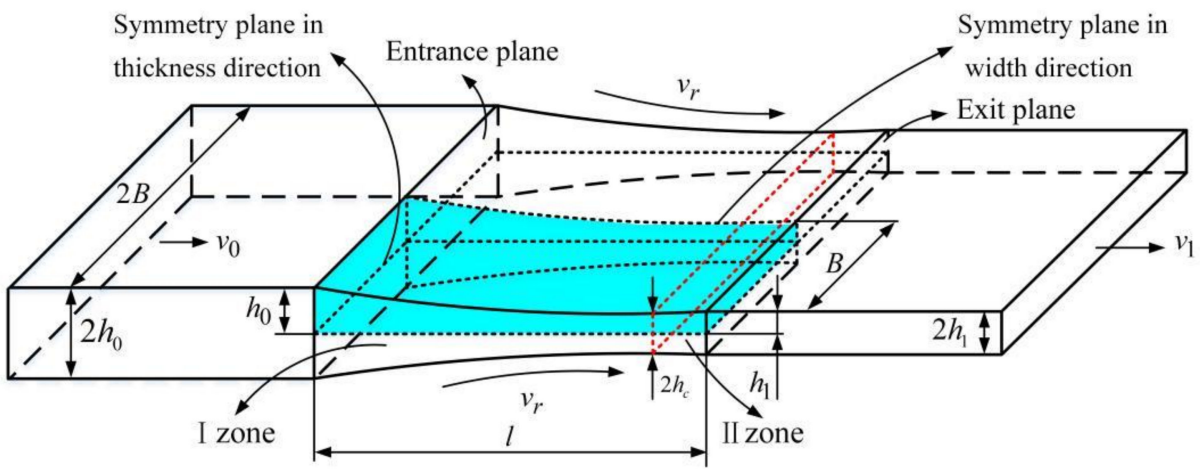

Figure 2. Definition sketch of the bite zone.

The roller surface equation and its first derivative equation of deformation zone II are respectively expressed as:

$$
\left\{\begin{array}{l}
h_{x}=h_{c}+R-\sqrt{R^{2}-x^{2}} \\
h^{\prime}{ }_{x}=\frac{x}{\sqrt{R^{2}-x^{2}}}=\tan \theta \\
x=R \sin \theta
\end{array}\right.
$$

\subsection{Strip Dynamic Velocity Field Model}

According to literature [14], in the dynamic rolling process, the principle of conservation of metal mass is affected by the vertical velocity of the rolls, which makes the principle of conservation of metal mass in static cannot be applied. As shown in Figure 3, it is assumed that the metal horizontal velocity on the vertical cross section is the same, and the strip is considered to be deformed in the plane to ignore the widening. Obviously, the volume of metal flowing in the shaded part is equal to the volume of metal flowing out. Therefore, the principle of conservation of metal mass in the entire deformation zone can be expressed as:

$$
v_{0} h_{0}+h_{c}^{\prime}\left(x+x_{0}\right)=v_{x} h_{x}
$$

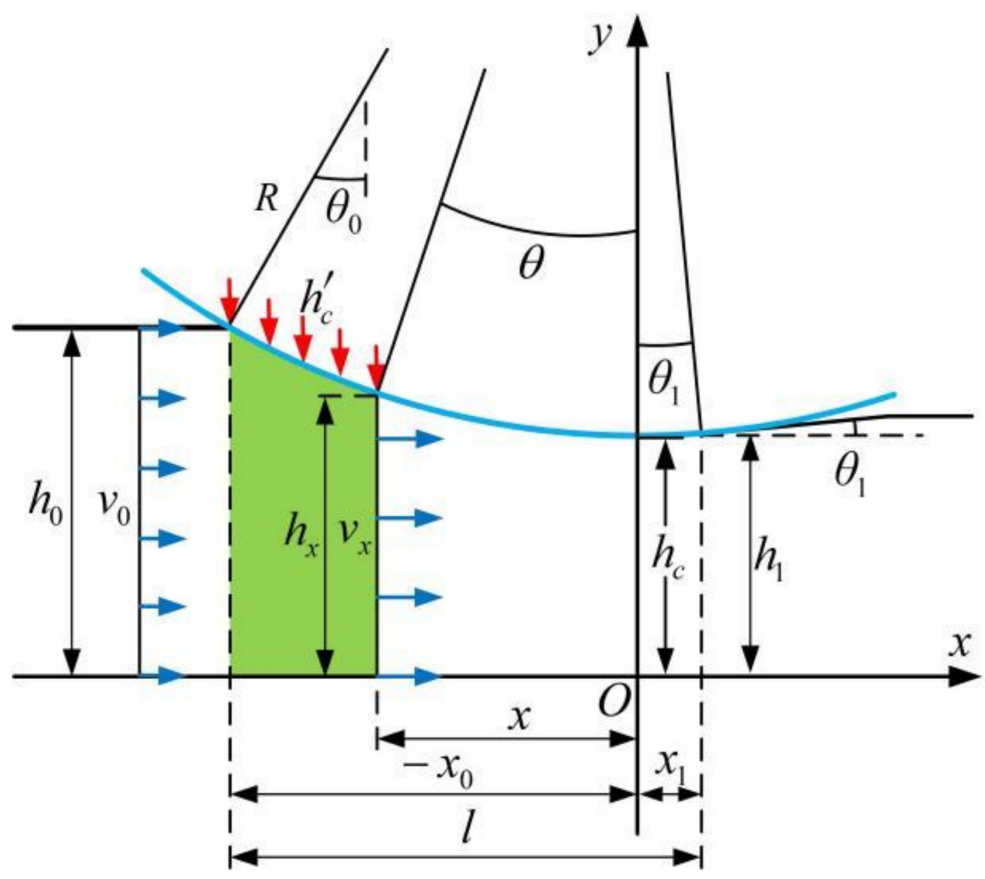

Figure 3. Conservation of metal mass in dynamic deformation zone. 
Considering the influence of the vertical velocity of the roll, the vertical velocity of the strip surface in the deformation zone can be expressed as:

$$
\left.v_{y}\right|_{y=h_{x}}=v_{x} h^{\prime}{ }_{x}-h_{c}^{\prime}
$$

It is assumed that the velocity from the center of the strip to the surface of the strip changes linearly in the vertical direction. And substituting the roller surface curve Equation (1) of zone I into Equations (3) and (4), the velocity field expression of zone I can be written:

$$
\left\{\begin{array}{l}
v_{x}=\frac{v_{0} h_{0}+h^{\prime}{ }_{c}\left(x+x_{0}\right)}{h_{c}+R-\sqrt{R^{2}-x^{2}}} \\
v_{y}=-\frac{v_{x} \tan \theta+h_{c}^{\prime}}{h_{x}} y
\end{array}\right.
$$

Similarly, the velocity field expression of zone II can be written:

$$
\left\{\begin{array}{l}
v_{x}=\frac{v_{0} h_{0}+h_{c}^{\prime}\left(x+x_{0}\right)}{h_{c}+R-\sqrt{R^{2}-x^{2}}} \\
v_{y}=\frac{v_{x} \tan \theta-h_{c}^{\prime}}{h_{x}} y
\end{array}\right.
$$

According to Equations (5) and (6), the strain rate of the strip in the deformation zone I and II can be obtained respectively:

$$
\begin{gathered}
\left\{\begin{array}{l}
\varepsilon^{\prime}{ }_{x}=\frac{v_{x} \tan \theta+h_{c}^{\prime}}{h_{x}} \\
\varepsilon^{\prime}{ }_{y}=\frac{-h_{c}^{\prime}-v_{x} \tan \theta}{h_{x}}
\end{array}\right. \\
\left\{\begin{array}{l}
\varepsilon^{\prime}{ }_{x}=\frac{h^{\prime}{ }_{c}-v_{x} \tan \theta}{h_{x}} \\
\varepsilon^{\prime}{ }_{y}=\frac{v_{x} \tan \theta-h_{c}^{\prime}}{h_{x}}
\end{array}\right.
\end{gathered}
$$

Obviously $\varepsilon^{\prime}{ }_{x}+\varepsilon^{\prime}{ }_{y}=0$ in Equations (7) and (8), Therefore, the dynamic velocity field model established in this paper is the kinematically admissible velocity field.

\subsection{Dynamic Boundary Condition Model}

The biggest difference from the static rolling process is that an additional deformation zone (deformation zone II) will appear when the roll gap is dynamically reduced.

As shown in Figure 4, at the strip exit position in the deformation zone, the strip thickness no longer decreases, so the vertical velocity must be zero, $\left.v_{y}\right|_{x=x_{1}}=0$. According to Equation (6):

$$
\frac{v_{1} \tan \theta_{1}-h_{c}^{\prime}}{h_{1}} y=0
$$

Equation (9) is simplified as:

$$
\tan \theta_{1}=\frac{h_{c}^{\prime}}{v_{1}}=\frac{x_{1}}{\sqrt{R^{2}-x_{1}^{2}}}
$$

Substituting Equation (6) into Equation (10) can be obtained:

$$
h^{\prime}{ }_{c}\left(h_{c}+R\right) \sqrt{R^{2}-x_{1}^{2}}-h_{c}^{\prime}\left(R^{2}-x_{1}^{2}\right)=x_{1}\left(v_{0} h_{0}+h^{\prime}{ }_{c} x_{0}\right)+h^{\prime}{ }_{c} x_{1}^{2}
$$

Since $x_{1}$ is much smaller than $R$, Equation (11) can be simplified to be written as:

$$
h^{\prime}{ }_{c} R h_{c}+h^{\prime}{ }_{c} R^{2}-h^{\prime}{ }_{c} R^{2}+h^{\prime}{ }_{c} x_{1}^{2}=x_{1}\left(v_{0} h_{0}+h^{\prime}{ }_{c} x_{0}\right)+h^{\prime}{ }_{c} x_{1}^{2}
$$

Then the expression of strip exit position can be written as:

$$
x_{1}=\frac{h^{\prime}{ }_{c} h_{c} R}{v_{0} h_{0}+h^{\prime}{ }_{c} x_{0}}
$$


Furthermore, the dynamic deformation zone length can be expressed as:

$$
l=x_{0}+x_{1}=\sqrt{2 R\left(h_{0}-h_{c}\right)-\left(h_{0}-h_{c}\right)^{2}}+\frac{h^{\prime}{ }_{c} h_{c} R}{v_{0} h_{0}+h^{\prime}{ }^{\prime} x_{0}}
$$

The model illustrates the effect of the roll vertical velocity on the exit position and length of the deformation zone.

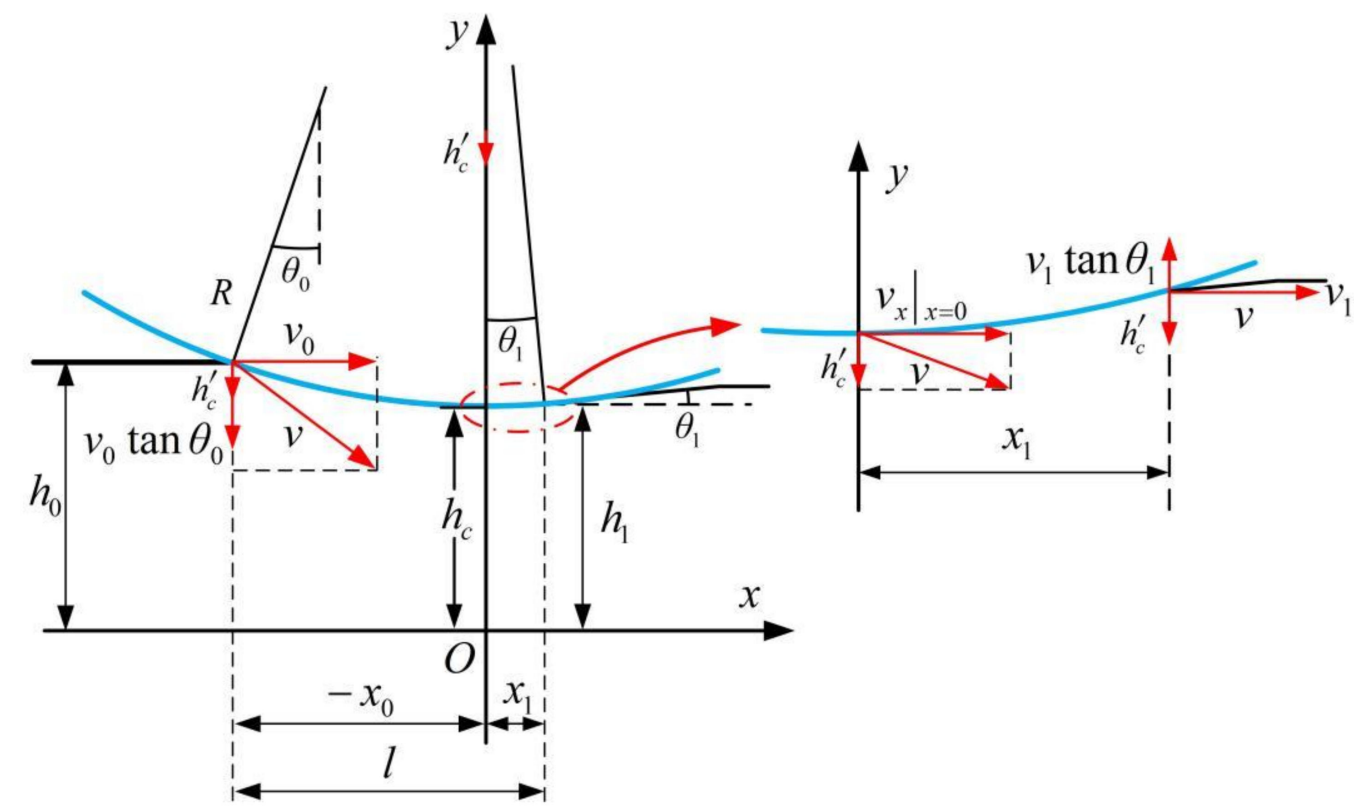

Figure 4. Changes of velocity and velocity components on the surface of the strip in the deformation zone.

\section{Total Power Function of Dynamic Rolling}

The total power equation during strip rolling is:

$$
W_{T}=\iiint_{V} k \Gamma d V-\iint_{S_{F}} F_{i} v_{i} d S
$$

The integral limit is shown in Figure 5. The vertical movement of the roll causes the rolling force to do work during the dynamic rolling process. The total power function can also be written as:

$$
W_{T}=W_{p}+W_{f}+W_{s}+W_{F}
$$

\subsection{Plastic Deformation Power Function}

The plastic deformation power is:

$$
W_{P}=4 \iiint_{V} k \Gamma d V
$$

where

$$
\begin{gathered}
\Gamma=\sqrt{\frac{2}{3}} \sqrt{\left(\varepsilon_{x}^{\prime}-\varepsilon_{y}^{\prime}\right)^{2}+\left(\varepsilon_{y}^{\prime}-\varepsilon_{z}^{\prime}\right)^{2}+\left(\varepsilon_{z}^{\prime}-\varepsilon_{x}^{\prime}\right)^{2}+\frac{3}{2}\left(\varepsilon_{x y}^{\prime 2}+{\varepsilon^{\prime}}_{y z}^{2}+\varepsilon_{z x}^{\prime 2}\right)} \\
\Gamma=\sqrt{4 \varepsilon_{x}^{\prime 2}+{\varepsilon^{\prime}}_{x y}^{2}}
\end{gathered}
$$

The von-Mises yield criterion is adopted, $\varepsilon_{x y}^{\prime}$ is not zero, but it has little effect on the final result and can be ignored. The specific proof has been placed in Appendix A. Under 
the assumption of plane deformation and uniform deformation, the shear strain strength equation can be simplified as:

$$
\Gamma=2 \varepsilon^{\prime} x
$$

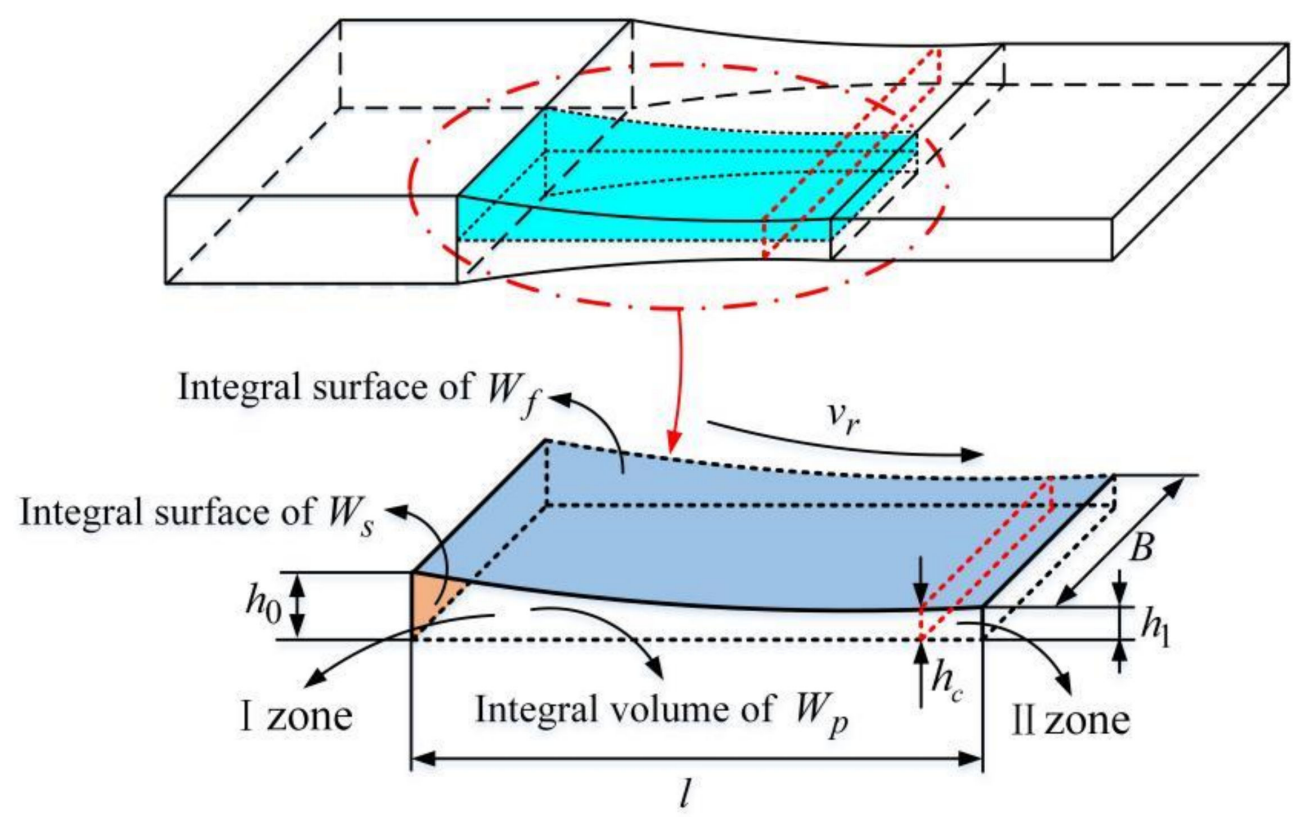

Figure 5. Integral limit of deformation zone.

In the process of roll gap reduction, the phenomenon of additional deformation zone (deformation zone II) appears, and the deformation rate, boundary conditions, and integral limits of deformation zones I and II are different, so they need to be solved separately. The plastic deformation power function can be written as:

$$
W_{P}=W_{P \mathrm{I}}+W_{P \mathrm{II}}
$$

In deformation zone I, the plastic deformation power is:

$$
\begin{aligned}
W_{P \mathrm{I}} & =4 \iint_{\mathrm{VI}} \int 2 k \varepsilon^{\prime}{ }_{x} d V=8 \int_{0}^{B} \int_{-x_{0}}^{0} \int_{0}^{h_{x}} k \varepsilon^{\prime}{ }_{x} d x d y d z \\
& =8 k B \int_{-x_{0}}^{0}\left(h^{\prime}{ }_{c}+v_{x} \tan \theta\right) d x=8 k B h^{\prime}{ }_{c} x_{0}+8 k B \int_{-x_{0}}^{0} v_{x} \tan \theta d x \\
& =8 k B h^{\prime}{ }_{c} x_{0}+8 k B \int_{-x_{0}}^{0} \frac{v_{0} h_{0}+h^{\prime}{ }_{c}\left(x+x_{0}\right)}{h_{x}} \tan \theta d x \\
& =8 k B\left[h^{\prime}{ }_{c} x_{0}-\left(v_{0} h_{0}+h^{\prime}{ }_{c} x_{0}\right) \ln \frac{h_{c}}{h_{0}}-h^{\prime}{ }_{c} \int_{-x_{0}}^{0} \frac{x \tan \theta}{h_{x}} d x\right] \\
& =8 k B\left[h^{\prime}{ }_{c} x_{0}-\left(v_{0} h_{0}+h^{\prime}{ }_{c} x_{0}\right) \ln \frac{h_{c}}{h_{0}}-h^{\prime}{ }_{c} Z\right]
\end{aligned}
$$

where

$$
\begin{gathered}
Z_{\mathrm{I}}=\sqrt{2 A_{1} h_{0}-h_{0}^{2}-A_{2}}+A_{1}\left[\frac{\pi}{2}-\arcsin \left(\frac{A_{1}-h_{0}}{R}\right)\right] \\
-\sqrt{A_{2}}\left[\arcsin \left(\frac{A_{1} h_{0}-A_{2}}{R h_{0}}\right)+\frac{\pi}{2}\right] \\
A_{1}=R+h_{c} \\
A_{2}=h_{c}^{2}+2 R h_{c}
\end{gathered}
$$


In deformation zone II, the plastic deformation power is:

$$
\begin{aligned}
W_{P \mathrm{II}} & =4 \iiint_{V \mathrm{II}} 2 k \varepsilon^{\prime}{ }_{x} d V=8 \int_{0}^{B} \int_{0}^{x_{1}} \int_{0}^{h_{x}} k \varepsilon^{\prime}{ }_{x} d x d y d z \\
& =8 k B \int_{0}^{x_{1}}\left(h^{\prime}{ }_{c}-v_{x} \tan \theta\right) d x=8 k B h^{\prime}{ }_{c} x_{1}-8 k B \int_{0}^{x_{1}} v_{x} \tan \theta d x \\
& =8 k B h^{\prime}{ }_{c} x_{1}-8 k B \int_{0}^{x_{1}} \frac{v_{0} h_{0}+h^{\prime}{ }_{c}\left(x+x_{0}\right)}{h_{x}} \tan \theta d x \\
& =8 k B\left[h^{\prime}{ }_{c} x_{1}-\left(v_{0} h_{0}+h^{\prime}{ }_{c} x_{0}\right) \ln \frac{h_{1}}{h_{c}}-h^{\prime}{ }_{c} Z_{\mathrm{II}}\right]
\end{aligned}
$$

where

$$
\begin{gathered}
Z_{\mathrm{II}}=\sqrt{2 A_{1} h_{1}-h_{1}^{2}-A_{2}}+A_{1}\left[\frac{\pi}{2}-\arcsin \left(\frac{A_{1}-h_{1}}{R}\right)\right] \\
-\sqrt{A_{2}}\left[\arcsin \left(\frac{A_{1} h_{1}-A_{2}}{R h_{1}}\right)+\frac{\pi}{2}\right]
\end{gathered}
$$

According to Equation (21), the plastic deformation power can be obtained as:

$$
W_{P}=8 k B\left[h^{\prime}{ }_{c}\left(x_{0}+x_{1}\right)-\left(v_{0} h_{0}+h^{\prime}{ }_{c} x_{0}\right) \ln \frac{h_{1}}{h_{0}}-h^{\prime}{ }_{c} Z\right]
$$

where

$$
\begin{aligned}
Z= & \sqrt{2 A_{1} h_{0}-h_{0}^{2}-A_{2}}+\sqrt{2 A_{1} h_{1}-h_{1}^{2}-A_{2}} \\
& -\sqrt{A_{2}}\left[\pi+\arcsin \left(\frac{A_{1} h_{1}-A_{2}}{R h_{1}}\right)+\arcsin \left(\frac{A_{1} h_{0}-A_{2}}{R h_{1}}\right)\right] \\
& +A_{1}\left[\pi-\arcsin \left(\frac{A_{1}-h_{0}}{R}\right)-\arcsin \left(\frac{A_{1}-h_{1}}{R}\right)\right]
\end{aligned}
$$

\subsection{Friction Power Function}

The friction power of deformation zone I and deformation zone II also need to be solved separately; the friction power is:

$$
W_{f}=W_{f} \mathrm{I}+W_{f \text { II }}
$$

As shown in Figure 6, in the deformation zone I, the velocity components of the rolls in the horizontal and vertical directions are respectively:

$$
\left\{\begin{array}{l}
v_{r x}=v_{r} \cos \theta \\
v_{r y}=-v_{r} \sin \theta-h_{c}^{\prime}
\end{array}\right.
$$

In the deformation zone I, the velocity difference between the surface of the strip and the roll is:

$$
\left\{\begin{array}{l}
\Delta v_{x}=v_{r} \cos \theta-v_{x} \\
\Delta v_{y}=v_{r} \sin \theta-v_{x} \tan \theta
\end{array}\right.
$$

Using the friction factor model proposed by Wanheim et al. [15] is:

$$
\tau_{f}=m k
$$

The friction power of deformation zone I is:

$$
W_{f \mathrm{I}}=4 \int_{-x_{0}}^{0} \int_{0}^{B} \tau_{f}\left|\Delta v_{f}\right| d F=4 \int_{-x_{0}}^{0} \int_{0}^{B}\left(\tau_{f x}\left|\Delta v_{x}\right|+\tau_{f y}\left|\Delta v_{y}\right|\right) d F
$$

where $\tau_{f x}=m k \cos \theta, \tau_{f y}=m k \sin \theta$. 


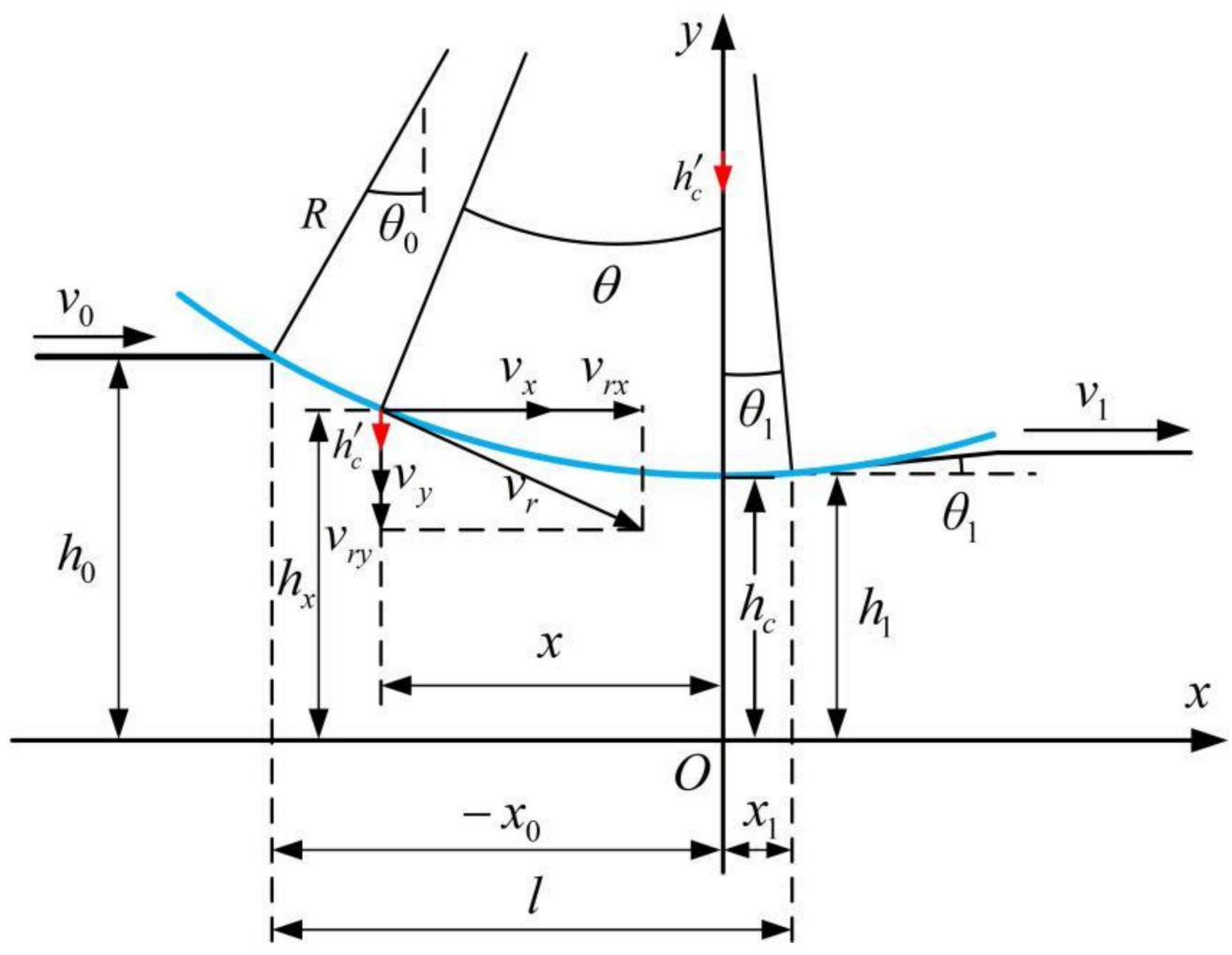

Figure 6. Dynamic rolling deformation zone.

The differential element is:

$$
d F=\sqrt{1+h^{\prime 2}} d x d y=\sec \theta d x d y
$$

According to Equations (32), (34) and (35), the friction power of deformation zone I is:

$$
\begin{aligned}
W_{f \mathrm{I}} & =4 m k \int_{-x_{0}}^{0} \int_{0}^{B}\left(\left|\Delta v_{x}\right| \cos \theta+\left|\Delta v_{y}\right| \sin \theta\right) \sec \theta d x d y \\
& =4 m k B \int_{-x_{0}}^{0}\left(\left|\Delta v_{x}\right|+\left|\Delta v_{y}\right| \tan \theta\right) d x \\
& =4 m k B\left(D_{\mathrm{I} 1}+D_{\mathrm{I} 2}\right)
\end{aligned}
$$

where

$$
\begin{gathered}
D_{\mathrm{I} 1}=\int_{-x_{0}}^{0}\left|\Delta v_{x}\right| d x \\
D_{\mathrm{I} 2}=\int_{-x_{0}}^{0}\left|\Delta v_{y}\right| \tan \theta d x
\end{gathered}
$$

The location of the neutral point must be discussed. The length of deformation zone II is much smaller than the length of deformation zone I. If the neutral point is in deformation zone II, the entire zone I is the backward slip zone, which is easy to cause slipping. Therefore, to ensure the stability of the rolling process, the neutral point is in deformation zone I when the process parameters are set reasonably. 
After the neutral point position is determined, Equation (37) can be expressed as:

$$
\begin{aligned}
D_{\mathrm{I} 1} & =\int_{-x_{0}}^{-x_{n}}\left(v_{r} \cos \theta-v_{x}\right) d x-\int_{-x_{n}}^{0}\left(v_{r} \cos \theta-v_{x}\right) d x \\
& =R v_{r}\left(\frac{\theta_{0}}{2}-\theta_{n}+\frac{\sin 2 \theta_{0}-2 \sin 2 \theta_{n}}{4}\right)+\left(v_{0} h_{0}+h^{\prime}{ }_{c} x_{0}\right)\left(\theta_{0}-2 \theta_{n}\right) \\
& -\frac{2 A_{1}\left(v_{0} h_{0}+h^{\prime}{ }_{c} x_{0}\right)}{\sqrt{A_{2}}}\left[\arctan \left(\sqrt{A_{3}} \tan \frac{\theta_{0}}{2}\right)-2 \arctan \left(\sqrt{A_{3}} \tan \frac{\theta_{n}}{2}\right)\right] \\
& +h^{\prime}{ }_{c}\left[R\left(1+\cos \theta_{0}-2 \cos \theta_{n}\right)+A_{1} \ln \frac{\left(A_{1}-R \cos \theta_{0}\right) h_{c}}{\left(A_{1}-R \cos \theta_{n}\right)^{2}}\right]
\end{aligned}
$$

where

$$
A_{3}=\frac{h_{c}+2 R}{h_{c}}
$$

Similarly, Equation (38) is expressed as:

$$
\begin{aligned}
D_{\mathrm{I} 2}= & \int_{-x_{0}}^{-x_{n}}\left(v_{r} \sin \theta-v_{x} \tan \theta\right) \tan \theta d x-\int_{-x_{n}}^{0}\left(v_{r} \sin \theta-v_{x} \tan \theta\right) \tan \theta d x \\
= & R v_{r}\left(\frac{\theta_{0}}{2}-\theta_{n}-\frac{\sin 2 \theta_{0}-2 \sin 2 \theta_{n}}{4}\right)-\left(v_{0} h_{0}+h^{\prime}{ }_{c} x_{0}\right)\left(\theta_{0}-2 \theta_{n}\right) \\
& -\frac{R\left(v_{0} h_{0}+h^{\prime}{ }_{c} x_{0}\right)}{A_{1}} \ln \frac{\tan \left(\frac{\pi+2 \theta_{0}}{4}\right)}{\tan ^{2}\left(\frac{\pi+2 \theta_{n}}{4}\right)}-h^{\prime}{ }_{c} R\left(1+\cos \theta_{0}-2 \cos \theta_{n}\right)+ \\
& \frac{2\left(v_{0} h_{0}+h^{\prime}{ }_{c} x_{0}\right) \sqrt{A_{2}}}{A_{1}}\left[\arctan \left(\sqrt{A_{3}} \tan \frac{\theta_{0}}{2}\right)-2 \arctan \left(\sqrt{A_{3}} \tan \frac{\theta_{n}}{2}\right)\right] \\
& -h^{\prime}{ }_{c} A_{1} \ln \frac{\left(A_{1}-R \cos \theta_{0}\right) h_{c}}{\left(A_{1}-R \cos \theta_{n}\right)^{2}}+\frac{h^{\prime}{ }_{c} R^{2}}{A_{1}}\left[\ln \frac{\left(A_{1}-R \cos \theta_{0}\right) h_{c} \cos ^{2} \theta_{n}}{\left(A_{1}-R \cos \theta_{n}\right)^{2} \cos \theta_{0}}\right]
\end{aligned}
$$

Finally, the friction power in deformation zone I can be obtained as:

$$
\begin{aligned}
W_{f \mathrm{I}}= & 4 m k B\left\{v_{r} R\left(\theta_{0}-2 \theta_{n}\right)-\frac{R\left(v_{0} h_{0}+h^{\prime}{ }_{c} x_{0}\right)}{A_{1}} \ln \frac{\tan \left(\frac{\pi+2 \theta_{0}}{4}\right)}{\tan ^{2}\left(\frac{\pi+2 \theta_{n}}{4}\right)}-\right. \\
& \frac{2 R^{2}\left(v_{0} h_{0}+h^{\prime}{ }_{c} x_{0}\right)}{A_{1} \sqrt{A_{2}}}\left[\arctan \left(\sqrt{A_{3}} \tan \frac{\theta_{0}}{2}\right)-2 \arctan \left(\sqrt{A_{3}} \tan \frac{\theta_{n}}{2}\right)\right] \\
& \left.+\frac{h^{\prime}{ }_{c} R^{2}}{A_{1}}\left[\ln \frac{\left(A_{1}-R \cos \theta_{0}\right) h_{c} \cos ^{2} \theta_{n}}{\left(A_{1}-R \cos \theta_{n}\right)^{2} \cos \theta_{0}}\right]\right\}
\end{aligned}
$$

Similarly, the horizontal and vertical velocity components of the roll in the deformation zone II are respectively:

$$
\left\{\begin{array}{l}
v_{r x}=v_{r} \cos \theta \\
v_{r y}=v_{r} \sin \theta-h_{c}^{\prime}
\end{array}\right.
$$

The velocity difference between strip and rolls is:

$$
\left\{\begin{array}{l}
\Delta v_{x}=v_{x}-v_{r} \cos \theta \\
\Delta v_{y}=v_{x} \tan \theta-v_{r} \sin \theta
\end{array}\right.
$$


According to Equations (34), (35), and (43), the friction power of deformation zone II can be obtained as:

$$
\begin{aligned}
W_{f \mathrm{II}} & =4 m k \int_{0}^{x_{1}} \int_{0}^{B}\left(\Delta v_{x} \cos \theta+\Delta v_{y} \sin \theta\right) \sec \theta d x d y \\
& =4 m k B \int_{0}^{x_{1}}\left(\Delta v_{x}+\Delta v_{y} \tan \theta\right) d x \\
& =4 m k B\left(D_{\mathrm{II} 1}+D_{\mathrm{II} 2}\right)
\end{aligned}
$$

where

$$
\begin{gathered}
D_{\mathrm{II} 1}=\int_{0}^{x_{1}} \Delta v_{x} d x \\
D_{\mathrm{II} 2}=\int_{0}^{x_{1}} \Delta v_{y} \tan \theta d x
\end{gathered}
$$

Equation (46) can be expressed as:

$$
\begin{aligned}
D_{\mathrm{II} 1}= & \int_{0}^{x_{1}}\left(v_{x}-v_{r} \cos \theta\right) d x \\
= & \frac{2 A_{1}\left(v_{0} h_{0}+h^{\prime}{ }_{c} x_{0}\right)}{\sqrt{A_{2}}} \arctan \left(\sqrt{A_{3}} \tan \frac{\theta_{1}}{2}\right)-\left(v_{0} h_{0}+h^{\prime}{ }_{c} x_{0}\right) \theta_{1} \\
& -R v_{r}\left(\frac{2 \theta_{1}+\sin 2 \theta_{1}}{4}\right)+R h^{\prime}{ }_{c}\left(\cos \theta_{1}-1\right)+A_{1} h_{c}^{\prime} \ln \left(\frac{A_{1}-R \cos \theta_{1}}{h_{c}}\right)
\end{aligned}
$$

Similarly, Equation (47) is expressed as:

$$
\begin{aligned}
D_{\mathrm{II} 2}= & \int_{0}^{x_{1}}\left(v_{x} \tan \theta-v_{r} \sin \theta\right) \tan \theta d x \\
= & \left(v_{0} h_{0}+h^{\prime}{ }_{c} x_{0}\right) \theta_{1}+\frac{R\left(v_{0} h_{0}+h^{\prime}{ }_{c} x_{0}\right)}{A_{1}} \ln \tan \left(\frac{\pi+2 \theta_{1}}{4}\right) \\
& -\frac{2 A_{1}\left(v_{0} h_{0}+h^{\prime}{ }_{c} x_{0}\right)}{\sqrt{A_{2}}} \arctan \left(\sqrt{A_{3}} \tan \frac{\theta_{1}}{2}\right)-R v_{r}\left(\frac{2 \theta_{1}-\sin 2 \theta_{1}}{4}\right) \\
& -h^{\prime}{ }_{c} R\left(\cos \theta_{1}-1\right)-h^{\prime}{ }_{c} A_{1} \ln \left(\frac{A_{1}-R \cos \theta_{1}}{h_{c}}\right)+\frac{h^{\prime}{ }_{c} R^{2}}{A_{1}} \ln \left(\frac{A_{1}-R \cos \theta_{1}}{h_{c} \cos \theta_{1}}\right)
\end{aligned}
$$

Finally, the friction power in deformation zone II can be obtained as:

$$
\begin{aligned}
W_{f \text { II }}= & 4 m k B\left[\frac{R\left(v_{0} h_{0}+h_{c}^{\prime} x_{0}\right)}{A_{1}} \ln \tan \left(\frac{\pi+2 \theta_{1}}{4}\right)-R v_{r} \theta_{1}\right. \\
& \left.+\frac{2 R^{2}\left(v_{0} h_{0}+h_{c}^{\prime} x_{0}\right)}{A_{1} \sqrt{A_{2}}} \arctan \left(\sqrt{A_{3}} \tan \frac{\theta_{1}}{2}\right)+\frac{h_{c}^{\prime} R^{2}}{A_{1}} \ln \left(\frac{A_{1}-R \cos \theta_{1}}{h_{c} \cos \theta_{1}}\right)\right]
\end{aligned}
$$

According to Equation (30), (42), (50), the frictional power during dynamic rolling is:

$$
\begin{aligned}
W_{f}= & 4 m k B\left\{\frac{R\left(v_{0} h_{0}+h^{\prime}{ }_{c} x_{0}\right)}{A_{1}} \ln \frac{\tan \left(\frac{\pi+2 \theta_{1}}{4}\right) \tan ^{2}\left(\frac{\pi+2 \theta_{n}}{4}\right)}{\tan \left(\frac{\pi+2 \theta_{0}}{4}\right)}\right. \\
& +R v_{r}\left(\theta_{0}-2 \theta_{n}-\theta_{1}\right)-\frac{2 R^{2}\left(v_{0} h_{0}+h^{\prime}{ }_{c} x_{0}\right)}{A_{1} \sqrt{A_{2}}}\left[\arctan \left(\sqrt{A_{3}} \tan \frac{\theta_{0}}{2}\right)\right. \\
& \left.-\arctan \left(\sqrt{A_{3}} \tan \frac{\theta_{1}}{2}\right)-2 \arctan \left(\sqrt{A_{3}} \tan \frac{\theta_{n}}{2}\right)\right] \\
& \left.+\frac{h_{c}^{\prime} R^{2}}{A_{1}}\left[\ln \frac{A_{1}-R \cos \theta_{0}}{\cos \theta_{0}}-2 \ln \frac{A_{1}-R \cos \theta_{n}}{\cos \theta_{n}}+\ln \frac{A_{1}-R \cos \theta_{1}}{\cos \theta_{1}}\right]\right\}
\end{aligned}
$$




\subsection{Shear Power Function}

The velocity discontinuity surface only exists at the entrance of the strip, and the velocity discontinuity value at the entrance is:

$$
\left.v_{y}\right|_{x=-x_{0}}=-\frac{v_{0} \tan \theta_{0}+h_{c}^{\prime}}{h_{0}} y
$$

According to Equation (52), the shear power at the entrance of the strip is:

$$
\begin{aligned}
W_{s} & =4 k \int_{0}^{h_{0}} \int_{0}^{B}\left|v_{y}\right|_{x=-x_{0}} \mid d y d z \\
& =4 k B \int_{0}^{h_{0}}\left(\frac{v_{0} \tan \theta_{0}+h^{\prime}{ }_{c}}{h_{0}} y\right) d y \\
& =2 k B h_{0}\left(v_{0} \tan \theta_{0}+h^{\prime}{ }_{c}\right)
\end{aligned}
$$

\subsection{Rolling Force Power Function}

In static rolling, the rolling force does not do work. In dynamic rolling, the roll has a vertical velocity and participates in work. The rolling force power function is:

$$
W_{F}=-2 F h^{\prime}{ }_{c}
$$

\subsection{Rolling Force Power Function}

Substituting Equations (28), (51), (53), (54) into Equation (17), the total power of the dynamic rolling process is:

$$
\begin{aligned}
W_{T}= & 4 k B\left\{2 h^{\prime}{ }_{c}\left(x_{0}+x_{1}\right)-2\left(v_{0} h_{0}+h^{\prime}{ }_{c} x_{0}\right) \ln \frac{h_{1}}{h_{0}}+\frac{h_{0}}{2}\left(v_{0} \tan \theta_{0}+h^{\prime}{ }_{c}\right)\right. \\
& +\frac{R\left(v_{0} h_{0}+h^{\prime}{ }_{c} x_{0}\right)}{A_{1}} \ln \frac{\tan \left(\frac{\pi+2 \theta_{1}}{4}\right) \tan ^{2}\left(\frac{\pi+2 \theta_{n}}{4}\right)}{\tan \left(\frac{\pi+2 \theta_{0}}{4}\right)}-2 h^{\prime}{ }_{c} Z- \\
& \frac{2 R^{2}\left(v_{0} h_{0}+h^{\prime}{ }_{c} x_{0}\right)}{A_{1} \sqrt{A_{2}}}\left[\arctan \left(\sqrt{A_{3}} \tan \frac{\theta_{0}}{2}\right)-2 \arctan \left(\sqrt{A_{3}} \tan \frac{\theta_{n}}{2}\right)\right. \\
& \left.-\arctan \left(\sqrt{A_{3}} \tan \frac{\theta_{1}}{2}\right)\right]+R v_{r}\left(\theta_{0}-2 \theta_{n}-\theta_{1}\right)+ \\
& \left.\frac{h_{c}^{\prime} R^{2}}{A_{1}}\left[\ln \frac{A_{1}-R \cos \theta_{0}}{\cos \theta_{0}}-2 \ln \frac{A_{1}-R \cos \theta_{n}}{\cos \theta_{n}}+\ln \frac{A_{1}-R \cos \theta_{1}}{\cos \theta_{1}}\right]\right\} \\
& -2 F h^{\prime}{ }_{c}
\end{aligned}
$$

Under the premise of known reduction rate, roll velocity, strip size, roll gap reduction velocity, roll radius, $W_{T}$ is only the function of neutral angle. According to the first principle, the true solution of the neutral angle minimizes the total power value, as follows:

$$
W_{\text {Tmin }}=W_{T}\left(\theta_{\text {nreal }}\right)
$$

The rolling torque and rolling force are respectively:

$$
\begin{gathered}
M=\frac{R_{0}\left(W_{P}+W_{f}+W_{s}\right)}{2 v_{r}} \\
F=\frac{M}{\psi \sqrt{2 R \Delta h}}
\end{gathered}
$$

where $\psi$ is the arm factor. 
Substituting Equations (57) and (58) into Equation (56) can be obtained:

$$
\begin{aligned}
W_{T \text { min }} & =W_{T}\left(\theta_{\text {nreal }}\right) \\
& =\left(W_{P}+W_{f}+W_{s}+W_{F}\right)_{\min } \\
& =\left(1-\frac{h^{\prime} R_{0 c}}{v_{r} \psi \sqrt{2 R \Delta h}}\right)\left(W_{P}+W_{f}+W_{s}\right)_{\min } \\
& =\left(1-\frac{h^{\prime} R_{0 c}}{v_{r} \psi \sqrt{2 R \Delta h}}\right)\left[W_{P}\left(\theta_{\text {nreal }}\right)+W_{f}\left(\theta_{\text {nreal }}\right)+W_{s}\left(\theta_{\text {nreal }}\right)\right]
\end{aligned}
$$

According to Equation (58), when the neutral angle is a real solution, the sum of $W_{P}, W_{f}$, and $W_{S}$ is the smallest. The actual solutions of rolling torque and rolling force are respectively:

$$
\begin{gathered}
M_{\min }=\frac{R_{0}\left(W_{P}+W_{f}+W_{s}\right)_{\min }}{2 v_{r}} \\
F_{\min }=\frac{M_{\min }}{\psi \sqrt{2 R \Delta h}}
\end{gathered}
$$

The actual roll radius during the rolling process is:

$$
R=R_{0}\left(1+2.2 \times 10^{5} \frac{F_{\min }}{4 B\left(\sqrt{h_{0}+h_{1}-2 h_{c}}+\sqrt{h_{1}-h_{c}}\right)^{2}}\right)
$$

The roll radius needs to be calculated iteratively with the rolling force until the accuracy is met.

\section{Results}

To verify the accuracy of the dynamic rolling force model. When the roll gap is reduced, a dynamic hot rolling experiment was carried out. The experiment was carried out on a laboratory two-high rolling mill with a roll radius of $40 \mathrm{~mm}$, The rolling mill equipment is shown in Figure 7a. The rolling mill adopts an electric pressing device equipped with a pressure sensor and a contact-type velocity measuring device, measuring the rolling force and roll velocity. At the same time, the rolling mill can control the velocity of roll gap change, the control interface of the rolling mill is shown in Figure $7 \mathrm{~b}$. Experiment with strips that meet the assumption of plane deformation. Use a resistance heating furnace to heat for $30 \mathrm{~min}$, then take out the strip, use a temperature measuring gun to measure the temperature before and after rolling and take the average value. After the strip is cooled, measure the thickness of the strip after rolling. Three different reduction rates were used for the experiments. When rolling each strip, perform static rolling first, after the rolling is stable, start variable thickness rolling, and finally the static rolling ends. The experimental material is $5052 \mathrm{Al}$, the experimental material is $5052 \mathrm{Al}$, the rolling temperature is $250{ }^{\circ} \mathrm{C}$, the strip thickness is $2 \mathrm{~mm}$, and there is no lubrication. Electronic Vernier calipers measure the thickness of the strip after rolling. The specific rolling parameters are shown in Table 1.

Table 1. Experimental parameters of dynamic rolling.

\begin{tabular}{cccc}
\hline Parameters & Strip 1 & Strip 2 & Strip 3 \\
\hline Entrance thickness $(\mathrm{mm})$ & 2 & 2 & 2 \\
Width $(\mathrm{mm})$ & 20.85 & 20.84 & 20.75 \\
Thicker zone exit thickness (mm) & 1.816 & 1.813 & 1.83 \\
Thinner zone exit thickness (mm) & 1.64 & 1.581 & 1.57 \\
Roll gap change velocity $(\mathrm{mm} / \mathrm{s})$ & 0.035 & 0.047 & 0.065 \\
\hline
\end{tabular}




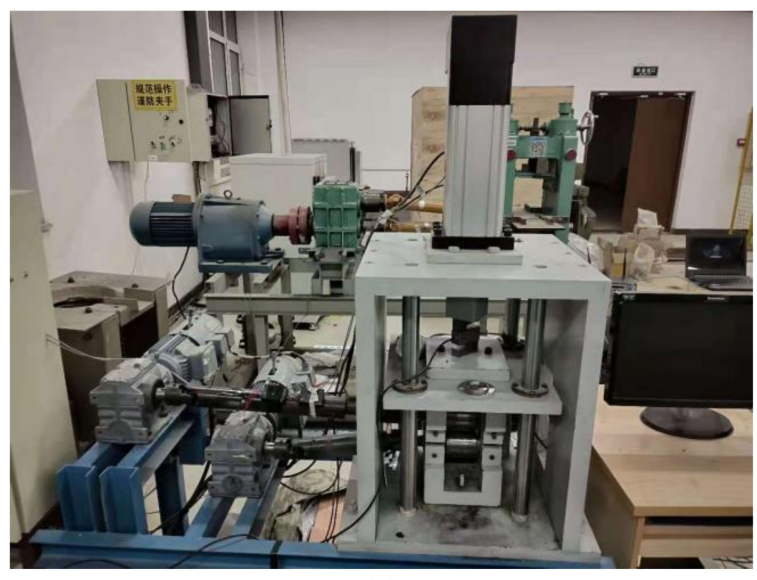

(a)

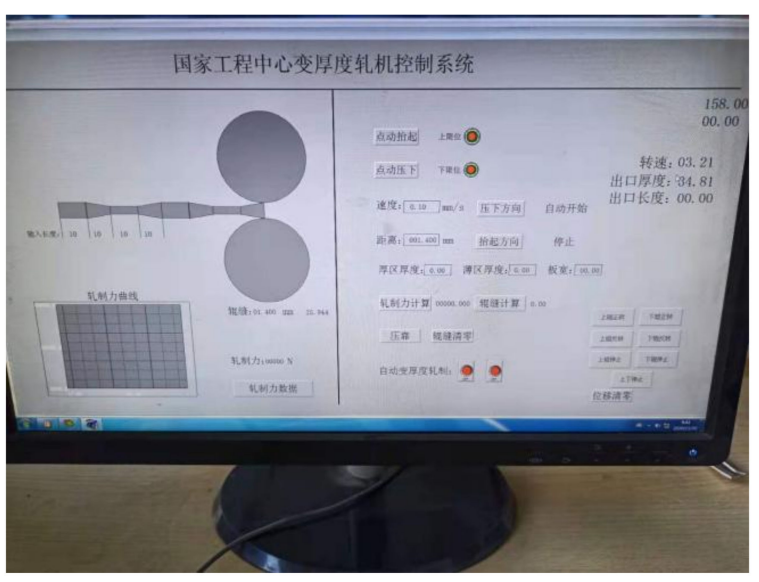

(b)

Figure 7. (a) Two-high asynchronous variable thickness experimental rolling mill; (b) Mill control interface.

The model of deformation resistance for the $5052 \mathrm{Al}$ used in the calculation is determined by Wang [16]:

$$
\sigma_{s}=180.73 \exp [-0.733(T-1)]\left(\frac{\overline{\varepsilon^{\prime}}}{10}\right)^{0.012+0.043 T}\left(1.048\left(\frac{\varepsilon}{0.2}\right)^{0.243-0.128 T}-0.048 \frac{\varepsilon}{0.2}\right)
$$

where $T=t / 300$, The unit of $\mathrm{t}$ is ${ }^{\circ} \mathrm{C}, \sigma_{s}=\sqrt{3} k, \overline{\varepsilon^{\prime}}$ is the average deformation rate during rolling.

During dynamic rolling, the deformation rate in the deformation zone is directly affected by the roll vertical velocity. The existing average deformation rate calculation model cannot fully reflect the law of metal deformation during dynamic rolling. Therefore, this paper adopts a new calculation model as follows:

$$
\overline{\varepsilon^{\prime}}=\frac{1}{\left(x_{0}+x_{1}\right)}\left(\int_{-x_{0}}^{0} \frac{v_{x} \tan \theta+h_{c}^{\prime}}{h_{x}} d x+\int_{0}^{x_{1}} \frac{h_{c}^{\prime}-v_{x} \tan \theta}{h_{x}} d x\right)
$$

There are few studies on the moment arm factor model. Pietrzyk [17] obtained a regression model of the force arm coefficient and the average thickness and contact arc length based on experimental research. This paper adopts the model form. Using Klarin et al. [18] hot rolling Al strip arm factor data, the final regression model of the arm factor of the hot rolling Al strip is:

$$
\psi=0.6673\left(\frac{\bar{h}}{l}\right)^{0.3133}
$$

Figure 8 shows the comparison between the calculation results of the dynamic model in this paper and the experimental results. Figure 8a shows shows the comparison result when the roll gap reduction velocity is $0 \mathrm{~mm} / \mathrm{s}$, which is a static rolling. The maximum error between the model calculation result and experimental result is $6.72 \%$. Figure $8 \mathrm{~b}-\mathrm{d}$ are the comparison results when the roll gap reduction velocity is $0.035 \mathrm{~mm} / \mathrm{s}, 0.047 \mathrm{~mm} / \mathrm{s}$, and $0.065 \mathrm{~mm} / \mathrm{s}$, respectively; they are the dynamic rolling process. The maximum error is $9.37 \%$, and the average error is only $3.8 \%$. The dynamic model can predict static rolling force and dynamic rolling force simultaneously, which is consistent with the experimental results, indicating that the model has high accuracy. 


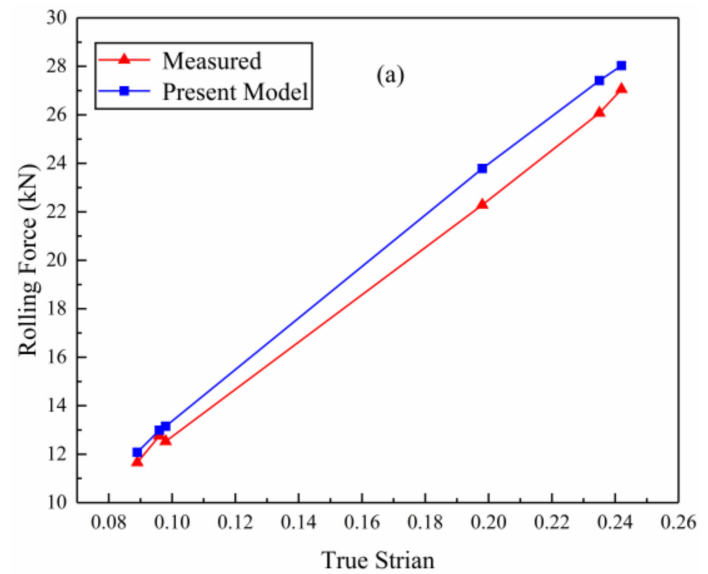

(a)

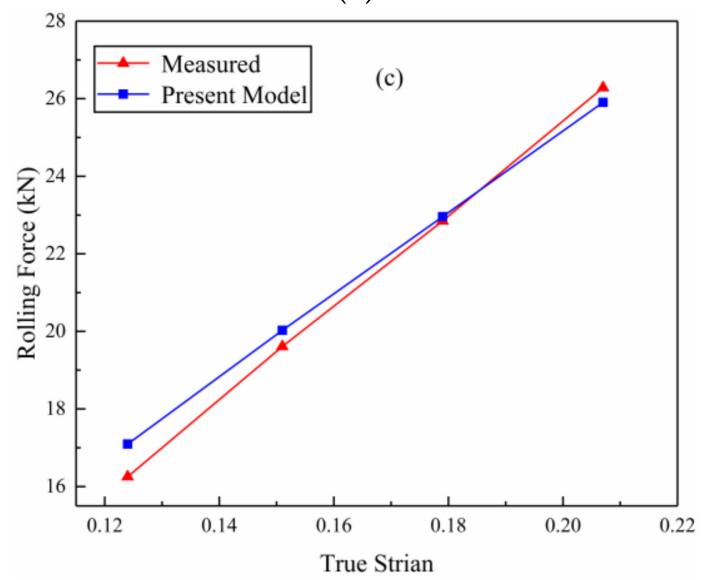

(c)

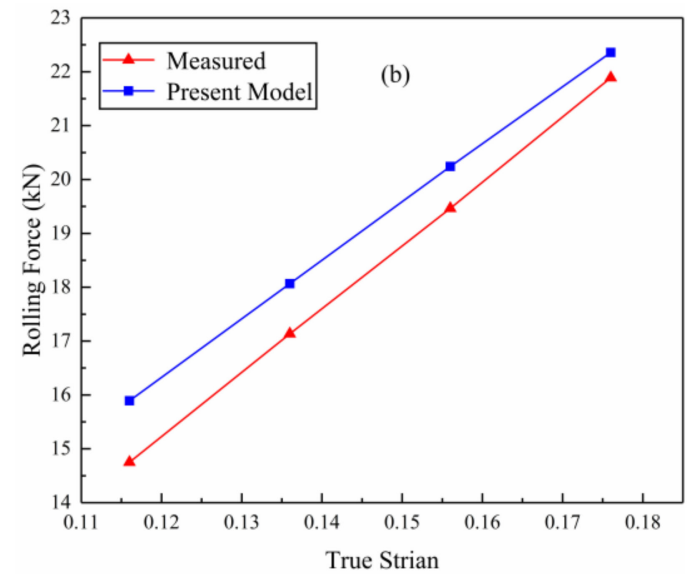

(b)

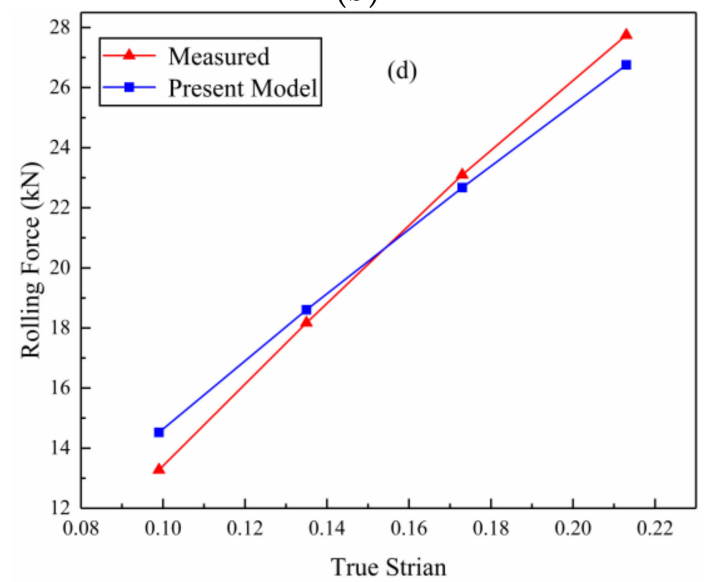

(d)

Figure 8. Comparison of theoretical model results and experimental results. The roll gap change velocity are respectively: (a) $0 \mathrm{~mm} / \mathrm{s}$; (b) $0.035 \mathrm{~mm} / \mathrm{s}$; (c) $0.047 \mathrm{~mm} / \mathrm{s}$; (d) $0.065 \mathrm{~mm} / \mathrm{s}$.

\section{Discussion}

As shown in Figure 9, the influence of the rolling velocity and roll gap reduction velocity on the dynamic rolling force is analyzed when the exit thickness is $1.816 \mathrm{~mm}$ (No change in thickness during analysis and calculation). When the roll gap reduction velocity is $0 \mathrm{~mm} / \mathrm{s}$, the rolling force increases with the increase of the rolling velocity. This phenomenon is mainly because the average deformation rate increases with the increase of the rolling velocity. At the same time, the deformation resistance increases with the increase of the average deformation rate. The rolling force increases with the increase of the deformation resistance. This shows that the rolling force increases with the increase of the average deformation rate. When the rolling velocity is constant, the rolling force increases with the increase of the roll gap reduction velocity, which is also due to the increase in the average deformation rate of the metal in the deformation zone due to the roll gap reduction velocity. However, when the roll gap reduction velocity is $0.04 \mathrm{~mm} / \mathrm{s}$, the rolling force increases initially and then starts to drop with the increase of the rolling velocity. When the roll gap reduction velocity increases to $0.06 \mathrm{~mm} / \mathrm{s}$, the rolling force gradually decreases with the increase of the rolling velocity. This phenomenon is contrary to the law of static rolling. When the roll gap reduction velocity exists, additional deformation zone II will appear. The length $x_{1}$ of the deformation zone II is affected by the roll gap reduction velocity rate to the rolling velocity. When the roll gap reduction velocity is constant, the increase of the rolling velocity will cause the decrease of $x_{1}$, affecting the deformation zone length. Therefore, the reduction of rolling force is mainly due to the reduction of the deformation zone length. 


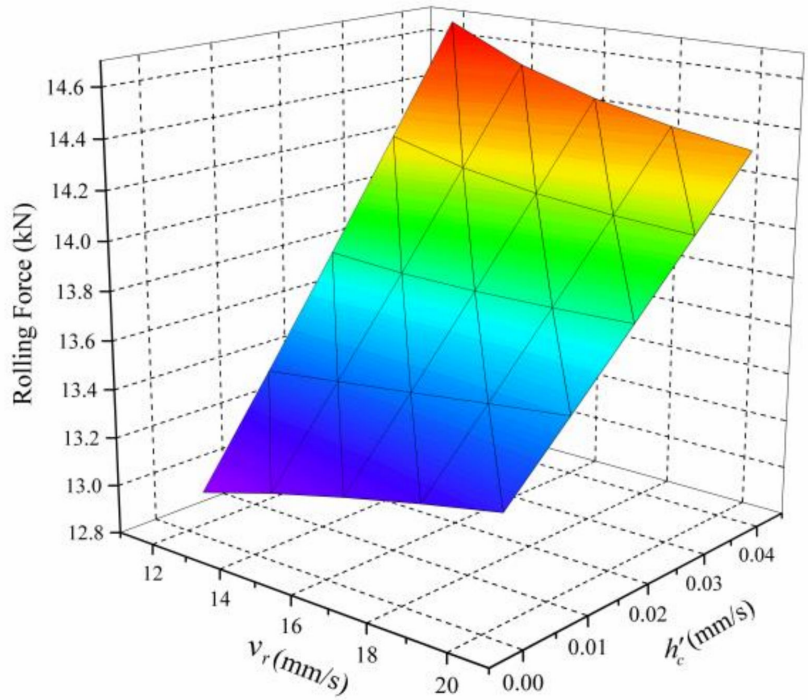

Figure 9. The influence of rolling velocity and roll gap reduction velocity on rolling force $\left(2 h_{1}=1.816 \mathrm{~mm}\right)$.

As shown in Figure 10, the influence of the rolling velocity and roll gap reduction velocity on the dynamic rolling force is analyzed when the exit thickness is $1.57 \mathrm{~mm}$ (No change in thickness during analysis and calculation). When the roll gap reduction velocity is $0 \mathrm{~mm} / \mathrm{s}$, the rolling force increases with the increase of the rolling velocity. When the rolling velocity is constant, the rolling force increases as the roll gap reduction velocity increases. The comparison with Figure 8 shows that the rolling force increases more extensively when the reduction amount increases significantly. It shows that when the reduction is significant, the average deformation rate will increase more significantly when the rolling velocity increases. When the roll gap reduction velocity is $0.04 \mathrm{~mm} / \mathrm{s}$, the rolling force increases initially and then starts to drop with the increase of the rolling velocity. Based on the above judgment, a higher roll gap reduction velocity is required to reduce rolling force from occurring. When the roll gap reduction velocity is $0.08 \mathrm{~mm} / \mathrm{s}$, the rolling force gradually decreases with the increase of the rolling velocity, but the decrease is smaller than when the exit thickness is $1.816 \mathrm{~mm}$.

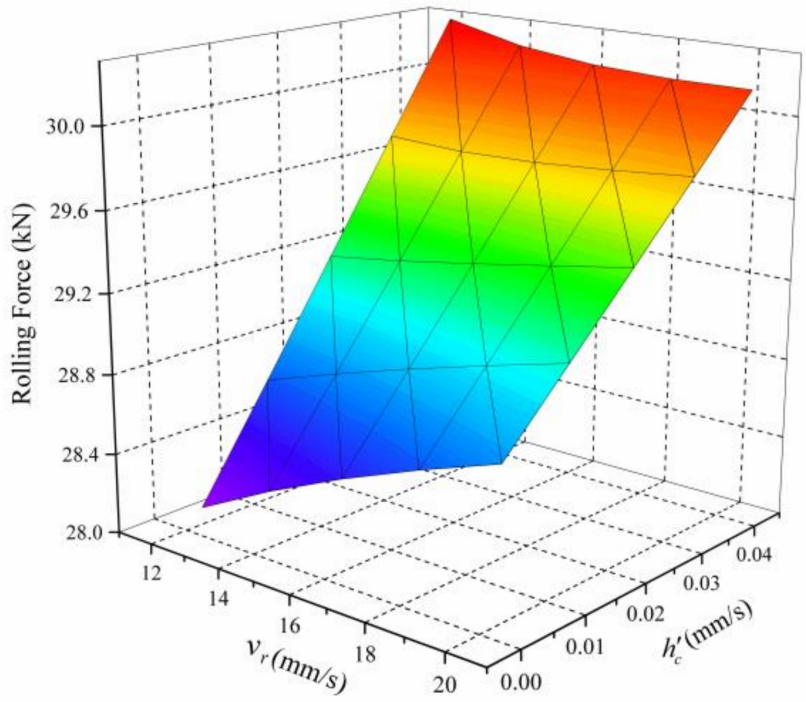

Figure 10. The influence of rolling velocity and roll gap reduction velocity on rolling force $\left(2 h_{1}=1.57 \mathrm{~mm}\right)$. 
In order to determine the reason for the reduction of rolling force during dynamic rolling, Figures 11 and 12 calculate the influence of rolling velocity and roll gap reduction velocity on the deformation zone length when the exit thickness is $1.816 \mathrm{~mm}$ and $1.57 \mathrm{~mm}$ (No change in thickness during analysis and calculation), respectively. As shown in Figures 10 and 11, when the rolling velocity is constant, the deformation zone length increases with the increase of the roll gap reduction velocity. When the roll gap reduction velocity is $0 \mathrm{~mm} / \mathrm{s}$, the deformation zone length increases slightly. Only deformation zone I exists, which is caused by the increase in the rolling force. When there is a roll gap reduction velocity, as the rolling velocity increases, the deformation zone length has been significantly reduced, which is mainly due to the reduction of the deformation zone II. With the increase of the roll gap reduction velocity, the increase in the average deformation rate cannot offset the effect of the reduction in the deformation zone length on the reduction of the rolling force. This indicates that the change in the deformation zone length plays a leading role in the change of the rolling force at this time. When the roll gap reduction velocity is $0.08 \mathrm{~mm} / \mathrm{s}$, the deformation zone length decreases sharply with the increase of the roll velocity, which further shows that the reduction of the rolling force is caused by the reduction of the deformation zone length.

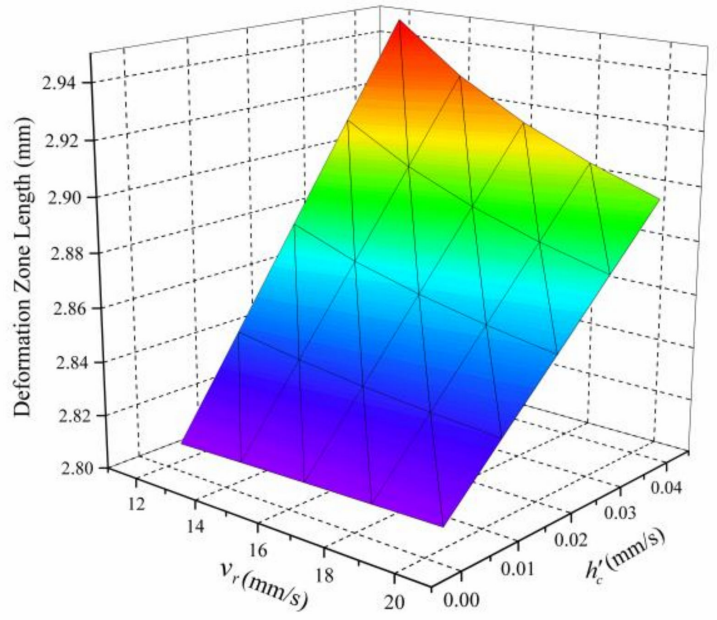

Figure 11. The influence of rolling velocity and roll gap reduction velocity on the deformation zone length $\left(2 h_{1}=1.816 \mathrm{~mm}\right)$.

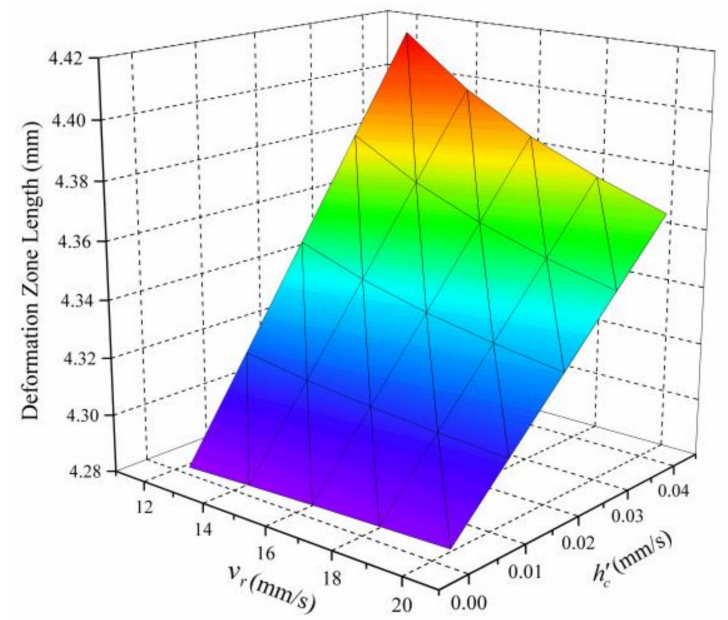

Figure 12. The influence of rolling velocity and roll gap reduction velocity on the deformation zone length $\left(2 h_{1}=1.57 \mathrm{~mm}\right)$. 
Through the analysis of Figures 9-12 and the mathematical expression of the dynamic rolling force model shows that the roll gap reduction velocity directly affects the average metal deformation rate and the deformation zone length and finally affects dynamic rolling force. Therefore, the dynamic model was modified to study the contribution of these two factors to the dynamic rolling force value. The dynamic boundary model modifies Equations (54) and (64) in this model, which ignores the effect of roll gap reduction velocity on the average metal deformation rate. The dynamic plastic deformation model only modifies Equation (14) in this model to $x_{1}=0$, which ignores the effect of roll gap reduction velocity on the deformation zone length. The static rolling force model is to modify Equation (14) in this model to $x_{1}=0$ and modify Equations (54) and (64) simultaneously. At this time, it is the static rolling.

According to Figure 13, the dynamic rolling model is compared with the calculation results of three modified models under different roll gap reduction velocities and exit thicknesses. By comparing the static model and dynamic model, the two factors significantly influence the dynamic rolling force. The influence of these two factors in the dynamic model is almost the same order of magnitude. In addition, this will depend of course on the alloy rolled and its strain rate sensitivity in particular.

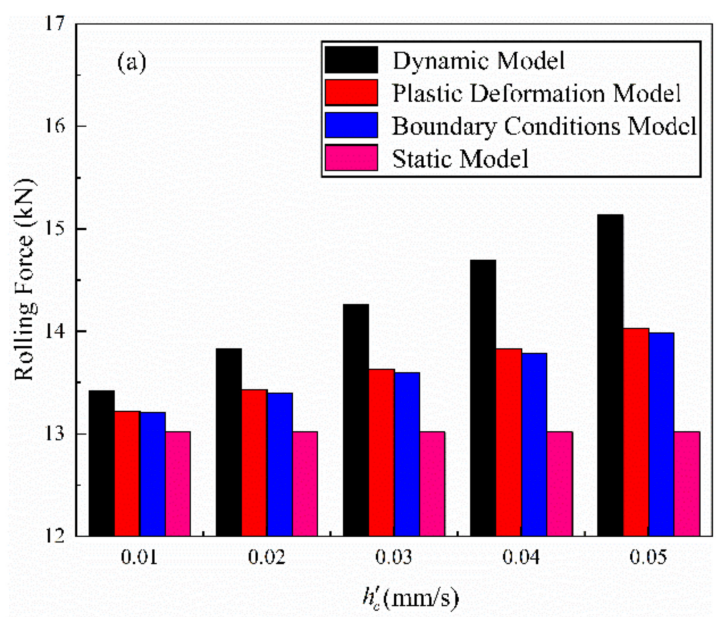

(a)

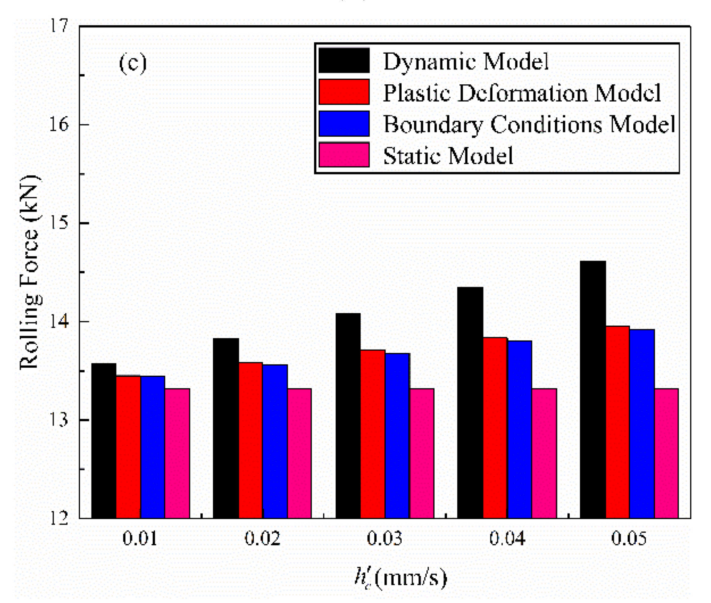

(c)

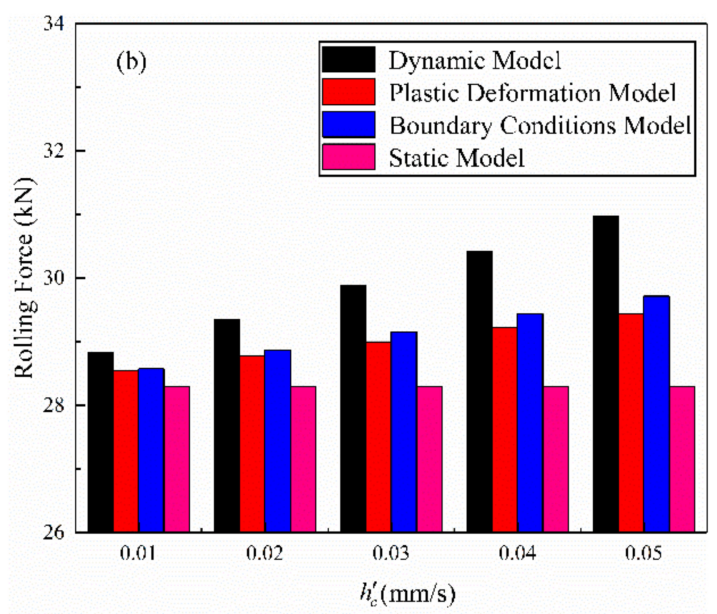

(b)

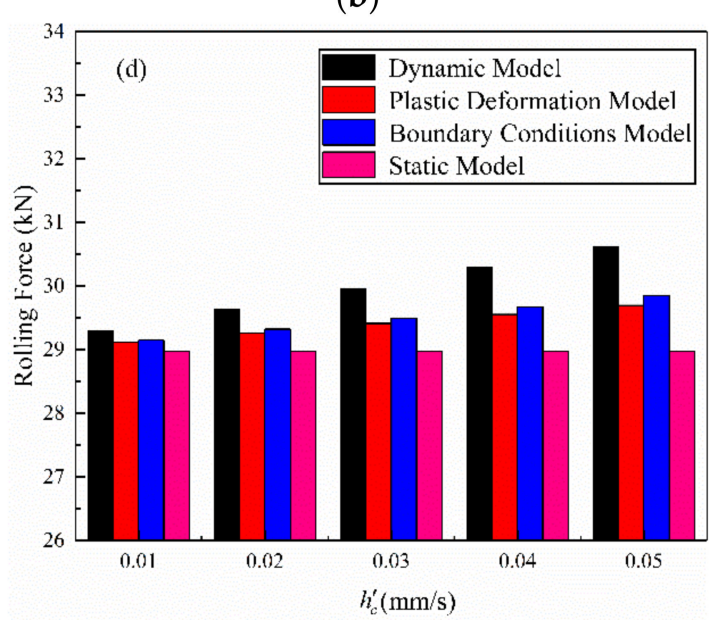

(d)

Figure 13. The contribution of the average metal deformation rate and dynamic boundary conditions to the dynamic rolling force value. The strip exit thickness and rolling velocity are respectively: (a) $1.816 \mathrm{~mm}, 12.5 \mathrm{~mm} / \mathrm{s}$; (b) $1.57 \mathrm{~mm}, 12.5 \mathrm{~mm} / \mathrm{s}$; (c) $1.816 \mathrm{~mm}, 20.5 \mathrm{~mm} / \mathrm{s}$; (d) $1.57 \mathrm{~mm}, 20.5 \mathrm{~mm} / \mathrm{s}$.

As shown in Figures 14 and 15, the influence of roll gap reduced velocity and rolling velocity on the neutral point position is analyzed when the exit thickness are $1.816 \mathrm{~mm}$ 
and $1.57 \mathrm{~mm}$ in dynamic rolling. When roll gap reduction velocity is $0 \mathrm{~mm} / \mathrm{s}$, the neutral point position is almost unchanged. When the rolling velocity is constant, the range of the neutral point moving to the exit position increases with the increase of the rolling velocity. When roll gap reduction velocity is constant, as the rolling velocity increases, the position of the neutral point moves to the exit position. The range of movement increases with the increase of the roll gap reduction velocity. Moreover, it can also be seen that under reasonable rolling parameters, the neutral point will not appear in deformation zone II, indicating that the assumptions of this model are correct.

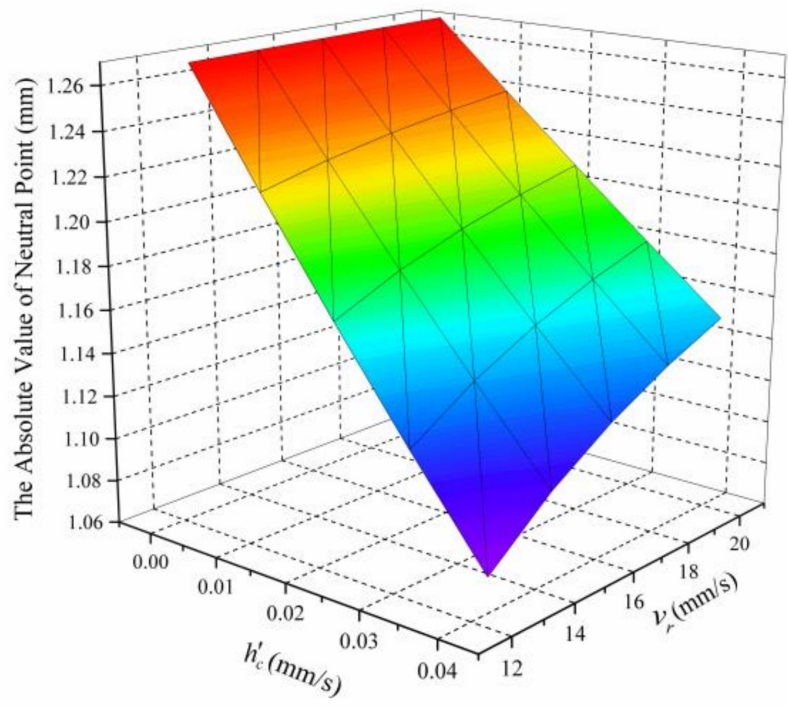

Figure 14. The influence of roll gap reduction velocity and rolling velocity on the position of neutral point $\left(2 h_{1}=1.816 \mathrm{~mm}\right)$.

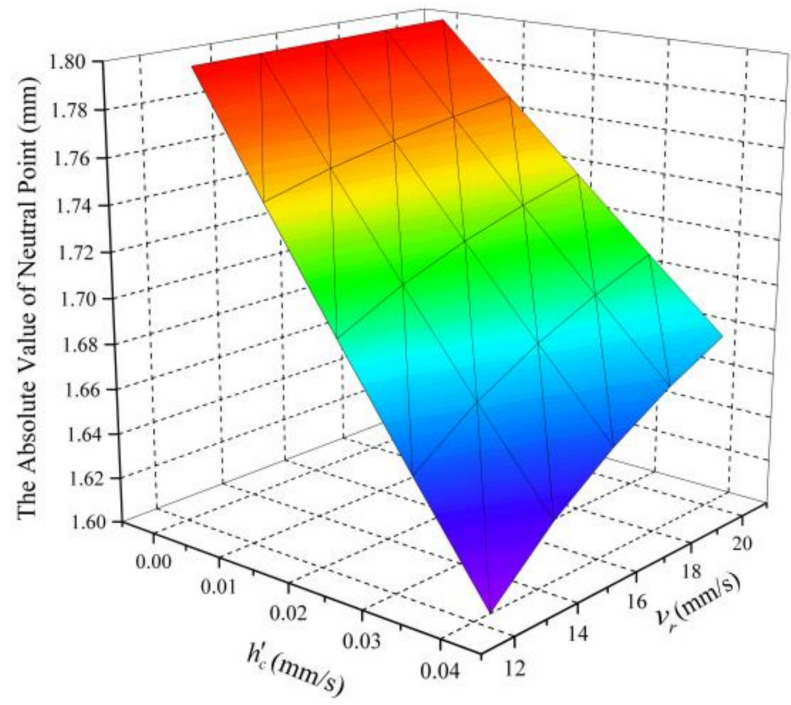

Figure 15. The influence of roll gap reduction velocity and rolling velocity on the position of neutral point $\left(2 h_{1}=1.57 \mathrm{~mm}\right)$.

\section{Conclusions}

(1) A new dynamic rolling model in roll gap reduction in the dynamic hot rolling process was established. This model successfully introduced the roll vertical velocity parameter into the rolling model, taking into account the influence of the roll vertical velocity on the deformation zone length and the plastic deformation rate. Compared 
with the dynamic rolling experiment, the average error of the model is $4 \%$, which has high accuracy.

(2) In the dynamic rolling, when the rolling velocity is constant, the rolling force increases with the increase of the roll gap reduction velocity. There is a critical value for the rolling reduction velocity. The critical value will increase with the increase of the reduction. When the critical value is reached, the rolling force will decrease with the increase of the rolling velocity, which is contrary to the law of static rolling.

(3) When the roll gap reduction velocity is constant, the length of the deformation zone decreases significantly with the increase of the rolling velocity, which is mainly caused by the reduction of the deformation zone length II.

(4) The change of the deformation zone length and the change of the metal deformation rate have a significant influence on the dynamic rolling force. When the reduction amount is small, the metal deformation rate changes and the contribution rate to the dynamic rolling force is comparatively large. When the reduction is significant, the deformation zone length changes and the contribution rate to the dynamic rolling force is more significant.

(5) As the roll gap reduction velocity increases, the position of the neutral point gradually moves to the exit direction. However, when the rolling parameters are within a reasonable range, the position of the neutral point is located in deformation zone I.

Author Contributions: Conceptualization, Y.Y. and Y.P.; methodology, Y.Y.; validation, Y.Y.; formal analysis, Y.P.; investigation, Y.P.; data curation, Y.Y.; writing—original draft preparation, Y.Y.; writingreview and editing, Y.Y.; visualization, Y.P.; supervision, Y.P.; project administration, Y.P.; funding acquisition, Y.P. All authors have read and agreed to the published version of the manuscript.

Funding: This research was funded by the National Key R\&D Program of China, grant number 2017YFB0304103 and the NSFC-Key Program of Regional Innovation and Development Joint Fund of China, grant number U20A20289.

Institutional Review Board Statement: Not applicable.

Informed Consent Statement: Informed consent was obtained from all subjects involved in the study.

Data Availability Statement: The technological data of rolling process used to support the findings of this study are included within the article.

Conflicts of Interest: The authors declare no conflict of interest.

\section{Appendix A}

In Equation (19), $\varepsilon_{x y}^{\prime}$ is not zero, but it has little effect on the final result and can be ignored. A proof is now provided. Since the length of deformation zone I is much longer than that of deformation zone II, and the proof steps are the same, only deformation zone I is used as an example to prove it.

According to the definition $\varepsilon_{x y}^{\prime}$ can be written as:

$$
\varepsilon_{x y}^{\prime}=\frac{\partial v_{y}}{\partial x}+\frac{\partial v_{x}}{\partial y}
$$

Substituting Equation (5) into Equation (A1) can be obtained:

$$
\begin{aligned}
\varepsilon^{\prime}{ }_{x y} & =\frac{\partial}{\partial x}\left(\frac{v_{x} h_{x}{ }_{x}-h^{\prime}{ }_{c}}{h_{x}} y\right) \\
& =\left(\frac{\varepsilon^{\prime}{ }_{x} h^{\prime}{ }_{x} h_{x}+v_{x} h^{\prime \prime}{ }_{x} h_{x}-v_{x} h^{\prime 2}{ }_{x}+h^{\prime}{ }_{c} h^{\prime}{ }_{x}}{h^{2} x}\right) y \\
& =\left(\frac{\varepsilon^{\prime}{ }_{x} h_{x}^{\prime}}{h_{x}}+\frac{v_{x} h^{\prime \prime}}{h_{x}}+\frac{h^{\prime}{ }_{c}-v_{x} h^{\prime}{ }_{x}}{h_{x}^{2}} h^{\prime}{ }_{x}\right) y \\
& =\left(\frac{\varepsilon^{\prime}{ }_{x} h_{x}^{\prime}}{h_{x}}+\frac{v_{x} h^{\prime \prime}{ }_{x}}{h_{x}}+\frac{\varepsilon^{\prime} h_{x}^{\prime}{ }_{x}}{h_{x}}\right) y
\end{aligned}
$$


where $h^{\prime \prime}{ }_{x}$ is the second derivative of the roller surface curve, and the expression is:

$$
\begin{aligned}
h^{\prime \prime}{ }_{x} & =\frac{1}{\sqrt{R^{2}-x^{2}}}+\frac{x^{2}}{\left(\sqrt{R^{2}-x^{2}}\right)^{3}} \\
& =\frac{1+h_{x}^{2}}{\sqrt{R^{2}-x^{2}}}
\end{aligned}
$$

According to formula (A2), $\varepsilon_{x y}^{\prime}$ is related to $y$. Using the median theorem, the average value of $\varepsilon_{x y}^{\prime}$ on the same $x$ section is:

$$
\bar{\varepsilon}_{x y}^{\prime}=\frac{\varepsilon_{x}^{\prime} h^{\prime}{ }_{x}+v_{x} h^{\prime \prime}{ }_{x}+\varepsilon^{\prime}{ }_{x}^{\prime}{ }_{x}}{2}
$$

In order to make Equation (19) become an equation only related to $\varepsilon^{\prime}{ }_{x}$, define parameter $\lambda$ as:

$$
\lambda=\frac{\int_{-x_{0}}^{0} \bar{\varepsilon}_{x y}^{\prime} d x}{\int_{-x_{0}}^{0} \varepsilon^{\prime} x d x}
$$

where $\lambda$ is a coefficient that has nothing to do with the variable $x$, and its expression is:

$$
\lambda=\frac{h_{c}^{\prime} \ln \frac{h_{c}}{h_{0}}+\frac{\left(v_{0} h_{0}+h_{c}^{\prime} x_{0}\right)}{2 h_{c}^{2}}\left(\theta_{0}+\frac{1-2 R h_{c}^{\prime}}{3} \theta_{0}^{3}\right)-\frac{R h_{c}^{\prime}}{8 h_{c}^{2}}\left(2 \theta_{0}^{2}-\theta_{0}^{4}-2 R \theta_{0}^{4}\right)}{\frac{R\left(v_{0} h_{0}+h_{c}^{\prime} x_{0}\right)}{2 h_{c}^{2}} \theta_{0}^{2}+\frac{R h_{c}^{\prime}}{h_{c}^{2}}\left(h_{c} \theta_{0}-\frac{\theta_{0}^{3}}{3}\right)}
$$

At this time, the relationship between $\varepsilon_{x y}^{\prime}$ and $\varepsilon^{\prime}{ }_{x}$ can be approximated by $\lambda$ :

$$
\varepsilon^{\prime}{ }_{x y} \approx \lambda \varepsilon^{\prime}{ }_{x}
$$

Substitute Equation (A7) into Equation (19), then divide by Equation (20), we can get:

$$
\eta=\frac{\sqrt{4{\varepsilon^{\prime}}_{x}^{2}+\lambda^{2}{\varepsilon^{\prime}}_{x}^{2}}}{\sqrt{4 \varepsilon_{x}^{\prime 2}}}=\frac{\sqrt{4+\lambda^{2}}}{2}
$$

$\eta W_{p}$ is the result when considering $\varepsilon^{\prime} x y$.

Taking the experimental parameters in this article as an example, $\eta W_{p}$ is only increased by $1 \%$ or less than $W_{p}$, and the error reflected in the rolling force is even smaller. So, it can be ignored.

\section{References}

1. Orowan, E. The calculation of roll pressure in hot and cold flat rolling. Proc. Inst. Mech. Eng. 1943, 150, 140-167. [CrossRef]

2. Sims, R.B. Calculation of roll force and torque in hot rolling mills. Proc. Inst. Mech. Eng. 1954, 168, 191-200. [CrossRef]

3. Li, S.; Wang, Z.G.; Ruan, J.H.; Liu, C.M.; Xu, Z.B. Hydrodynamics method and its application in hot strip rolling. Steel Res. Int. 2017, 168, 1600220. [CrossRef]

4. Chen, S.X.; Li, W.G.; Liu, X.H. Calculation of rolling pressure distribution and force based on improved Karman equation for hot strip mill. Int. J. Mech. Sci. 2014, 89, 56-63. [CrossRef]

5. Oh, S.I.; Kobayashi, S. An approximate method for a three-dimensional analysis of rolling. Int. J. Mech. Sci. 2014, 17, 293-305. [CrossRef]

6. Sezek, S.; Aksakal, B.; Can, Y. Analysis of cold and hot plate rolling using dual stream functions. Mater. Des. 2008, 29, 84-96. [CrossRef]

7. Zhang, S.H.; Deng, L.; Zhang, Q.Y.; Li, Q.H. Modeling of rolling force of ultra-heavy plate considering the influence of deformation penetration coefficient. Int. J. Mech. Sci. 2019, 159, 373-381. [CrossRef]

8. Liu, Y.M.; Ma, G.S.; Zhao, D.W.; Zhang, D.H. Analysis of hot strip rolling using exponent velocity field and MY criterion. Int. J. Mech. Sci. 2015, 98, 126-131. [CrossRef]

9. Li, S.; Wang, Z.G.; Guo, Y.F. A novel analytical model for prediction of rolling force in hot strip rolling based on tangent velocity field and MY criterion. J. Manuf. Process. 2019, 47, 202-210. [CrossRef]

10. Hu, P.H.; Ehmann, K.F. A dynamic model of the rolling process. Part I: Homogeneous model. Int. J. Mach. Tool Manuf. 2000, 40, 1-19. [CrossRef] 
11. Gao, Z.Y.; Liu, Y.; Zhang, Q.D.; Liao, M.L.; Tian, B. Chatter model with structure-process-control coupled and stability analyses in the cold rolling system. Mech. Syst. Signal Process. 2020, 140, 106692. [CrossRef]

12. Cao, L.; Li, X.; Wang, Q.L.; Zhang, D.H. Vibration analysis and numerical simulation of rolling interface during cold rolling with unsteady lubrication. Tribol. Int. 2021, 153, 106604. [CrossRef]

13. Hu, P.H.; Ehmann, K.F. A dynamic model of the rolling process. Part II: Inhomogeneous model. Int. J. Mach. Tool Manuf. 2000, 40, 21-31. [CrossRef]

14. Yang, Y.B.; Peng, Y. Dynamic rolling model based on uniform deformation. J. Manuf. Process. 2020, 58, 1334-1347. [CrossRef]

15. Wanheim, T.; Bay, N.; Petersen, A.S. A theoretically determined model for friction in metal working processes. Wear 1974, 28, 251-258. [CrossRef]

16. Wang, W.W. The Study on the Temperature Calculation Model of 5052 Al Plate in Hot Continuous Rolling. Master's Thesis, Central South University, Changsha, China, 2021.

17. Pietrzyk, M. A graphical method for predicting roll force and torque. J. Mech. Work. Technol. 1984, 10, 67-75. [CrossRef]

18. Klarin, K.; Mouton, J.P.; Lundberg, S.E. Application of computerized slip-line-field analysis for the calculation of the lever-arm coefficient in hot-rolling mills. J. Mater. Process. Technol. 1993, 36, 427-446. [CrossRef] 